\title{
Are East African Pastoralists Truly Conservationists?
}

\section{by Lore M. Ruttan and Monique Borgerhoff Mulder}

Controversy exists among anthropologists, conservation biologists, and development workers as to whether the concept of the "ecologically noble savage" is a myth. Central to this debate are the problem of how to identify conservationist behavior and the issue of whether sound management of common property is likely to evolve. While social scientists have documented instances of restraint in the use of resources, those who adopt an evolutionary perspective are challenged to identify the selective mechanisms whereby such altruistic conservation acts might be maintained in a population. Here a game-theoretical approach is used to analyze the case of pastoralist grazing reserves. We demonstrate that under some conditions conservation can be the result of narrow self-interest and there is no collective-action problem. However, the range of these conditions is much broader for wealthy individuals, and thus the wealthy may also find it advantageous to coerce others into conserving. In conclusion, we propose an extension of the definition of conservation that is of greater generality for use in nonforaging populations and incorporates the essential political element of how conflicts over resource use are resolved.

LORE M. RUTTAN is a postdoctoral researcher with the "Sea Around Us" project of the Fisheries Centre, University of British Columbia (2204 Main Mall, Vancouver, B.C., Canada V6T IZ4). Born in I96I, she was educated at the University of Chicago (A.B., I984) and the University of Minnesota (M.S., I988). Her research interests are human behavioral ecology and commonproperty resource management. She has published (with C. Packer) "The Evolution of Cooperative Hunting" (American Naturalist I 32:159-98) and "Closing the Commons: Cooperation for Gain or Restraint?" (Human Ecology 26:43-66).

Monique borgerhoff mulder is Professor of Anthropology at the University of California, Davis and chair of the Graduate Group in Human Ecology. She was born in 1953 and educated at the University of Edinburgh (B.Sc., M.A.) and Northwestern University (Ph.D., I 987). She has held fellowships at the University of Michigan (1987-89) and the University of Bielefeld (I99I-92). Her publications include "Bridewealth and Its Correlates: Quantifying Changes over Time" (CURRENT ANTHROPOLOGY 36:573-603), "Demographic Transition: Are We Any Closer to an Evolutionary Explanation?" (Trends in Ecology and Evolution I 3 : 266-70), and "Brothers and Sisters: How Sibling Interactions Affect Optimal Parental Allocations" (Human Nature 9:I I9-62).

The present paper was submitted 26 VIII 98 and accepted I 8 XII 98; the final version reached the Editor's office 20 III 99.

I. We thank Michael Alvard, Robert Boyd, Peter Coppolillo, Hillard Kaplan, Peter Richerson, Eric Smith, and two anonymous referees
"Conservation" commonly refers to the maintenance of genetic, species, and ecosystem diversity in the natural abundance in which they occur (OTA I987). It has been more difficult to reach consensus on the identification of behaviors that might aptly be called "conservation." According to evolutionary ecologists, conservation acts are by definition costly and entail the sacrifice of immediate rewards in return for delayed ones. Thus conservation is potentially altruistic if resources are not held privately. In contrast, researchers with more applied interests typically consider an intent to conserve, as evidenced by institutional design, to be sufficient. In this paper, we take a position that stems from neither of these camps but may serve as a bridge between them. Retaining both the assumption of individual self-interest and the methodological rigor that characterize an evolutionary ecological approach, we build a model that incorporates the asymmetries in power and interest that typify most human communities. We argue (I) that individuals act to maximize economic efficiency, but this may be different from the short-term economic efficiency predicted by optimal foraging models; $(2)$ that economically motivated decisions may thus have the fortuitous but important consequence of conserving resources; and (3) that strategies having conservation as a consequence can be maintained in a population despite the heterogeneous interests of individuals, but because conservation may not be in the interests of all individuals it may be achieved by coercion.

\section{Does the "Ecologically Noble Savage" Exist?}

\section{LIVING IN HARMONY WITH NATURE}

Ethnographers and sociocultural anthropologists often argue that indigenous peoples live in balance with their environment and, more generally, in harmony with nature. They base this view on the observation that small populations with limited technology subsist on plant and animal species without driving these resources to extinction and without causing long-term degradation of the environment (e.g., Alcorn I989, Posey and Balée I989, IWGIA I992). A putative harmonious relationship of foraging populations with their environment is further suggested by the apparent long-term stability of such populations, a point first made by Birdsell (I958) and much reiterated. Such equilibria (be they stable or oscillating) among predators and their prey are also observed in nonhuman species. Thirty years ago biologists attributed such systems to the behavior of predators, speculating that a "prudent predator" (Slobodkin I968) chooses to spare the prime-aged reproductive prey in order to secure a sustainable harvest for the future. This view has become outdated among biologists, who now examine equilibria within the broader perspective of den-

for helpful comments and discussion. Lore Ruttan was supported by a MacArthur Fellowship from the Institute on Global Conflict and Cooperation, University of California. 
sity-dependent and independent processes or focus on chaotic, condition-dependent systems. By contrast, most anthropologists still hold that prudence is a goal of subsistence hunters, as embodied in their conservation ethic (e.g., Nelson 1982, Kay I985, Zann I989, Durning I993) and knowledge of natural history (e.g., Johannes I978, I98I). Accordingly, indigenous peoples are attributed the reputation of being natural conservationists or, in Redford's (I990) more spirited epithet, "ecologically noble savages."

As might be expected, evolutionary ecologists question whether indigenous peoples are natural conservationists, their primary objection being theoretical. Individuals cannot be expected to limit present harvests of resources for the purpose of conserving them for future use if this behavior entails a cost (Winterhalder 1977, Smith 1983, Hames 1987, Alvard 1993, Beckerman and Valentine 1996, Low 1996, Winterhalder and $\mathrm{Lu} \mathrm{1997).}$ The rationale of this critique is that such restraint is altruistic if the benefits are shared by all but the costs are borne individually (Gordon I954, Scott I955). Thus, the notion of conservation entails all the theoretical problems associated with the evolution of cooperation, altruism, and collective action. ${ }^{2}$

\section{DEFINITIONS AND TESTS OF CONSERVATION ACTS}

Driven by these theoretical objections, evolutionary anthropologists began conducting field examinations of whether the "ecologically noble savage" exists, with most studies focusing on foraging populations. Hames (I987) suggested testing for conservation behavior by pitting its predictions against others derived from optimalforaging theory, which he termed "efficiency hypotheses." Efficiency is predicated on two assumptions: that more food enhances individual fertility and survival and that time spent acquiring food has opportunity costs (Kaplan and Hill I 992). It should be noted, however, that most optimal-foraging models are based on the assumption that exploitation of a resource has no effect on its future abundance (but see Benson and Stephens I996). Hence, efficiency hypotheses predict that foragers' preychoice decisions will maximize the rate at which resources are taken per unit time spent foraging by an individual. Under this hypothesis, resources will be harvested independent of the effect of this harvesting on

2. Human evolutionary ecologists have not been alone in their critique of the concept of an ecologically noble savage. As early as I 972 Leach pointed out that history shows quite unambiguously that humans generally fail to reach a balanced relationship with their environment or to demonstrate restraint with respect to their use of resources. He and subsequently Bennett (I976) and Jochim (I98I) speculated on the nature of the environmental conditions that might favor conservation acts (see Chapman I985 for an empirical test of their ideas). A common thread to these critiques is that the enormous environmental knowledge that indigenous populations exhibit cannot in itself guarantee that these societies avoid resource depletion over the long term, though such knowledge is of course of potentially immense value for resource managers, both indigenous and external (for a recent balanced treatment see Stevens I997). resource availability in the future. (We use the term "efficiency" here to refer to individual-level behavior as opposed to socially efficient solutions and not in the more technical sense of a benefit-to-cost ratio.)

While predictions based on optimal-foraging theory were already well specified (e.g., Stephens and Krebs I986), conservation hypotheses were as yet undetermined. Hames captured the essence of the meaning of conservation by emphasizing short-term restraint for long-term benefits (I987:93). ${ }^{3}$ From Alvard (I995) and especially Smith's (I995) commentary thereon, "conservation" refers to actions that "are intended to and do in fact prevent or at least mitigate resource depletion, species extinction, or habitat degradation" (p. 8Io). However, because both restraint and long-term environmental effects are so hard to identify in field situations, empirical tests of these two hypotheses have tended to view conservation acts simply as those that are not predicted by optimal-foraging theory (but see Alvard I995 for empirical exceptions and Alvard 1993 for a conceptual distinction between "selfish" and "altruistic" conservation). All the same, Hames's initiative generated valuable empirical studies. Without exception, these studies show that foragers choose the prey that maximizes economic returns per unit time spent foraging (or efficiency) (Hames 1987; Alvard 1993, 1994, I995; see also Stearman 1994, Vickers I994), seriously weakening the notion that populations living in apparent harmony with their environments necessarily practice conservation. Furthermore, foragers eschew prey-choice decisions that might minimize any impact on the population dynamics of their prey; for example, they do not avoid females and individuals of peak reproductive value (Alvard I995, I998).

The failure to find any hint of conservation in traditional foragers' hunting behavior has stimulated intriguing speculations by evolutionary ecologists (and resource economists) on where and when conservation might be observed in human societies in terms of the explicit trade-off between short-term costs and long-term benefits (Clark 1973; Hames I987, I991; Rogers I991). ${ }^{4}$ Summarizing the work of these authors, there are four principal conditions for conservation. First, there must be mechanisms whereby outsiders can be excluded from resources. Second, there must be within-group mechanisms to enforce restraint and penalize cheaters. Third, there must be mechanisms whereby resources can be inherited by offspring, such that long-term benefits can accrue to conservers. Fourth, there must be no alternative forms of investment yielding higher rates of return than the conserved resource. However, Alvard (I998) notes that many of these conditions may have been rare during much of human evolutionary history (e.g., in the environment of evolutionary adaptedness).

3. Hames's definition parallels political economists' earlier revival and use of the term "stinting."

4. Other social scientists take a similar approach (e.g., Ostrom I990). 
CRITICISMS OF THE EVOLUTIONARY ECOLOGICAL APPROACH

Despite these advances in evolutionary ecologists' ability to identify and predict conservation acts in humans, there is still little consensus on the validity of such analyses (see, e.g., Stearman's and others' comments on Alvard I995). Many detractors argue against ruling out the practice of conservation among traditional foragers on the basis of their hunting behavior alone. They note that plants can be harvested much more benignly than animals and it is therefore easier for foragers to manage plant than game resources. As Stearman (I995) tellingly notes, ethnobotanists are the most vocal proponents of the view that indigenous people possess an intrinsic conservation ethic. There is clearly much merit in distinguishing hunting and gathering activities. Furthermore, there are good reasons that evolutionary ecologists would not expect hunted resources to be conserved. Foragers' principal prey species (mammals and birds) are commonly unpredictable in time and space, often highly dispersed, and sometimes migratory. For this reason, restraint today may afford no future benefit to the restrainers, let alone to their offspring. Plants, by comparison, are predictable in time and in space, and strategies with payoffs in the future might be adaptive. Critics such as Alcorn (I995) are therefore right to argue that a focus on hunting makes it all too easy to reject the conservation hypothesis among foragers. They would be wrong, however, to infer a conservation ethic concerning game resources.

A second objection relates to evolutionary ecologists' tendency to ignore the implications of power differentials between indigenous peoples and their settled neighbors, at least insofar as such inequities exist in the contemporary world. Evolutionary ecologists are well aware of this problem (Hames I 99I, Hill I 995). There are, however, at least two ways in which such power differentials might influence whether foragers can afford the luxury of acting as conservationists. First, if foragers do not hold secure autonomous rights to their land, what motivation can they have for practicing short-term restraint for longterm benefit? Why spare that giraffe today if a villager who can sell the meat in a market will take it tomorrow? This, of course, is a similar problem to the one discussed above-no long-term incentives for restraint. It is also part of the more general problem of how a commons can degenerate into an open-access system (Cordell I984; Bromley and Cernea I989; Jodha I987, cited in Feeny et al. I990). The second effect of power differentials is that insofar as hunter-gatherers are nowadays relegated to habitats that are marginal to their ancestral foraging areas, overexploitation of natural resources may become a necessity. An individual who is hungry today literally cannot afford the costs associated with short-term restraint (see also Alvard I998). Since both marginalization and acute power differentials are endemic among contemporary foragers and their neighbors, it is perhaps unlikely that conservation acts will be observed by contemporary observers. Alcorn (I995), however, makes precisely the opposite case in arguing that conservation practices are most likely to be seen in communities where there are conflicts of interests over resources and where overharvesting is a problem, that is, among marginalized groups. Thus, she suggests that the absence of conservation in the studies mentioned above simply reflects the relative abundance of resources in contemporary Amazonian communities and the dissolution of traditional means of enforcement.

The third and most important objection is that viewing conservation as an alternative to optimal foraging is an oversimplification. To differentiate conservation from efficiency, Hames and others assumed that optimal-foraging strategies are economically more efficient than conservation strategies, since, by definition, efficiency strategies maximize rates of return. Yet in practice rates of return are measured over the period of time in which the behavior in question is employed, usually on the order of hours. While this simplification was a practical necessity (with recognized shortcomings [see, e.g., Alvard I995:790; Hill I995]), it ignores the fact that in many areas of human endeavor economic efficiency is synonymous with sustained long-term production, a point also recognized by Berkes (I987) and others. Indeed, a strategy can be both environmentally friendly and economically rational, particularly where producers have more control over the resources they depend on than foragers. Under such conditions, conservation can be isomorphic with economic efficiency. In a nutshell, then, our point is not that evolutionary anthropologists are unaware of this time-scale problem or that they think that short-term restraint (conservation) is antithetical to individual self-interest but only that the significance of longer-term outcomes has been undervalued in empirical analyses of when, where, and why humans act as conservationists.

There is a fourth objection: that studies challenging the ecologically-noble-savage viewpoint are inflammatory with respect to the increasingly contentious political debates surrounding conservation and indigenous affairs (e.g., Alcorn I991, I995; Puri 1995). However, as Hill (I995) and many others make quite clear, conservation performance is not a valid reason for divesting indigenous peoples of their land. Indeed, indigenous groups demonstrating no conservation ethic under traditional conditions readily become conservationists as they adjust to the novel political and economic environment (Vickers 1994). A dispassionate understanding of where, when, and how humans engage in conservation is central to the development of strategies designed to develop sustainable patterns of resource use, to protect human rights, and to conserve biodiversity. We give no further attention to this critique but appreciate that dis-

\footnotetext{
5. Berkes (1987:89) makes the point that the goals of foraging efficiency and long-term conservation are not necessarily mutually exclusive and notes that the Cree themselves have difficulty separating the economic reasons (maximizing harvest efficiency) from the biological reasons (keeping the harvest at sustainable levels) behind their practices. Bulmer (I982) makes a similar argument regarding foraging practices of the Kalam of Papua New Guinea.
} 
claimers such as those emphasized above should always be prominent.

If our goal is to identify conservation acts in a more realistic economic and political world-in other words, to extend the search for an ecologically noble savage beyond the realm of hunting into the realm of food producers-then we need to expand our intellectual tool kit. Here we focus on pastoralists and adopt a different approach, one with much in common with the work of institutional economists, to the question of whether and how conservation acts might be maintained in a population. We retain the lay notion of conservation as shortterm restraint aimed at maximizing long-term benefits, but we reject the false corollary that efficiency is maximized only by maximizing short-term benefits. Because restraint on the part of some individuals opens up the possibility for cheating on the part of others, we pose the problem as a frequency-dependent game (see also Borgerhoff Mulder and Ruttan 2000). Our approach differs from most other treatments of collective action in that we examine whether restraint can emerge as an evolutionary stable strategy (ESS) when the population is heterogeneous with respect to wealth and therefore interests. Finally, we speculate on the possibilities for coercion to enter into the game. We use the classic example of a pastoral grazing reserve to show how heterogeneous interests in resource use can generate conservation outcomes. Ironically, the example of grazing reserves was also used (albeit inappropriately) by Hardin (I968) to illustrate the tragedy of the commons.

\section{Identifying Conservation among Pastoralists}

GRAZING RESERVES AND THE BARABAIG

Despite claims that pastoralist communities are responsible for overgrazing and environmental degradation (e.g., Lamprey I983), pastoralists are also commonly credited with practicing a conservation ethic. Much of the evidence that supports the overgrazing hypothesis is indeed equivocal (Sandford I 983, Homewood and Rodgers I99 I, Ellis and Swift I988). Furthermore, there are numerous detailed observations of herdsmen following grazing regimes (e.g., McCabe I990, Lane I 996), observing stocking regulations (e.g., Netting I976), and maintaining institutional land use practices (e.g., Galaty I994) that seem to protect grasslands from overuse. Though an evolutionary ecologist might read these provisional conclusions with some skepticism, there is ample evidence, both published and in our own field observations, that herdsmen do adopt strategies regulating the use of grazing areas in the vicinity of their settlements and that these can be successful in preserving range quality. The evolutionary ecological puzzle, then, is this: are these strategies costly, and if so what mechanisms serve to maintain them?

We take as an example the Barabaig, a subsection of the Datoga (Tomikawa I979, Borgerhoff Mulder, Sieff, and Merus 1989). They keep cattle and small stock on the semiarid plains of Hanang District, in northern Tanzania, supplementing their diet with grain obtained through exchange of livestock or shifting cultivation. Rainfall averages $600 \mathrm{~mm} /$ year, and periodic droughts occur (Lane I996). The dominant vegetation in the area is Acacia and Commiphora woodland, interspersed with open grassland. In general, as in most East African pastoral groups, grazing is free to all members of the local population.

Barabaig grazing patterns have been well described by Lane (1996) in the context of a more applied study that exposes the devastating social and ecological consequences of land alienation. Barabaig maintain fixed homesteads throughout the year on the Barabaig Plains, but soon after the rainy season starts (November -December) young men and women take their family herds to the Basotu Plains, where high-quality forage is available, setting up temporary camps on these wet-season pastures. Since there are no permanent water sources here, at the end of the rainy season (May-July) the herds are driven back down the Rift escarpment to the Barabaig Plains, a journey of two to three days (see Western I975 for a similar water-limited grazing pattern in East Africa). Throughout the next four to eight months, grazing becomes increasingly scarce on the dry-season reserve, with the result that animals lose condition even in years of normal rainfall and in drought years are forced to enter more densely wooded areas with associated elevated risks of disease and predation. Among the Barabaig, therefore, grazing is dictated by water needs (specifically the permanent water of the wells at Lake Balangda Lelu on the Barabaig Plains), the desire to diversify livestock intake, and the opportunity to capitalize on grass species whose productivity varies seasonally. Most critical for our present purposes, herders need to preserve the grasslands surrounding their permanent homesteads on the Barabaig Plains. If they do not, all households suffer. Since the Barabaig land use system is somewhat unusual in its details, particularly in its preservation of nearby dry-season reserves for later use, we justify its use as an example in the discussion below.

Pastoralists almost universally move their herds around in response to the vagaries of climate and a variety of other constraints so as to make the best use of grazing and water resources. To facilitate this form of foraging, they operate systems of common land tenure. Lane (I996) describes the extensive rights, obligations, and prohibitions associated with the common property system of the Barabaig, as well as the customary rules regulating its use and the tripartite jural structure involved in rule enforcement. For instance, a herder who takes his livestock into seasonally protected areas will first be brought to a judicial moot and asked to desist from the offense. If he refuses he may be fined and, in more serious cases, cursed. Very similar observations come from other pastoral groups and indeed have stimulated a whole literature attesting to the conservation ethic among pastoralists.

In our attempt to develop a game in which respect for dry-season reserves can be maintained within a popu- 


\begin{tabular}{|c|c|c|}
\hline & Rich Cooperates & Rich Defects \\
\hline & $\alpha m d+A^{*} m /(f+m)-C$ & $\alpha m d+(A-\alpha m d) * m /(f+m)$ \\
\hline $\begin{array}{c}\text { Poor } \\
\text { Cooperates }\end{array}$ & $\alpha f d+A * f /(f+m)-C$ & $\alpha f d+(A-\alpha m d) * f /(f+m)-C$ \\
\hline & $\alpha m d+(A-\alpha f d) * m /(f+m)-C$ & $A * m /(f+m)$ \\
\hline $\begin{array}{l}\text { Poor } \\
\text { Defects }\end{array}$ & $\alpha \mathrm{fd}+(\mathrm{A}-\alpha \mathrm{fd}) * \mathrm{f} /(\mathrm{f}+\mathrm{m})$ & $A * f /(f+m)$ \\
\hline
\end{tabular}

Fig. I. Payoff matrix for a game between two herders, one rich and one poor. Payoffs to the poor herder are in the lower left corner of each cell while payoffs to the rich herder are in the upper right.

lation, we use the Barabaig as an example because it is clearly described and simple to conceptualize. Many intriguing details of the system described by Lane (I996) are, however, omitted from the algebra with a view to keeping the model both simple and general. For example, we do not even include the fact that the forage on the Basotu Plains is seen to be of higher nutritional value than that on the Barabaig Plains; including this difference would only increase the level of cooperation observed. We do, however, allow differences in herd size among rich and poor herders (as a varying ratio), since this is universal among Datoga (Lane I990, Borgerhoff Mulder I99I) and most other pastoral groups (e.g., Fratkin and Smith I994). We explore the dimension of heterogeneity in wealth because the present modeling exercise was stimulated by the idea that richer herders (with presumably a greater investment in the pastoral sector) might be more inclined to favor conservation.

\section{A GAME WITH ASYMMETRICAL PAYOFFS}

To keep the analysis simple we imagine that there are two types of herders: rich herders, who own many cattle $(m)$, and poor herders, who own few $(f)$. The cattle belonging to rich and poor herders are identical insofar as each eats an amount $(\alpha)$ each day. Payoffs $(f)$ to rich and poor herders are asymmetrical, since their value depends on the number of cattle owned. We model the environmental conditions described above by imagining that the wet-season pastures are available for a limited number of days, $D$, and that the dry-season reserves have a fixed area and thus a fixed amount of grass available, $A$. The decision we wish to analyze is whether a herder should "cooperate" and move his livestock to the wet-season pastures during the rainy season or "defect" and remain in the dry-season reserves year-round. By defecting, a herder avoids paying the cost, $C$, of moving livestock and setting up a wet-season camp, but less forage may then be available. The currency is measured in arbitrary units of livestock survival and productivity, which are an unspecified function of grass intake, how far the livestock need to travel, and the availability of labor within the household.

We begin our analysis by constructing a $2 \times 2$ matrix of the payoffs (fig. I). If both herders cooperate, then the poor one receives the amount obtained by grazing $f$ cattle in the wet-season pastures for $D$ days, plus a share $(f / f+m)$ of the dry-season reserves minus the cost of traveling to the wet-season pastures:

$$
f(p c \mid r c)=\alpha f D+A^{*} f /(f+m)-C .
$$

If the poor herder cooperates when the rich herder defects, the dry-season reserves are reduced every day the rich herder grazes his many cows there by $\alpha m D$, and thus the poor herder obtains

$$
f(p c \mid r d)=\alpha f D+(A-\alpha m D)^{*} f /(f+m)-C
$$

In contrast, if the poor herder is the one to defect while the rich herder cooperates $(p d \mid r c)$, then the former's herd eats an amount $\alpha f D$ from the dry-season reserves while the rich herder's cattle are away during the wet season. During the dry season, the poor herder receives his share of what is left in the dry-season reserves $(A-\alpha f D)$ and does not pay any cost of going to the wet-season pastures. The poor herder thus obtains

$$
f(p d \mid r c)=\alpha f D+(A-\alpha f D)^{*} f((f+m) .
$$


If all herders defect, then a poor herder receives only his share of the dry-season reserves:

$$
f(p d \mid r d)=A^{*} f /(f+m) .
$$

The payoffs to a rich herder are obtained by switching the $m^{\prime}$ 's and $f^{\prime}$ s in equations $\mathrm{I}-4$.

In order to determine how well a two-person game can be extrapolated to a whole village, we consider how the game might be played among $n$ players. This is an interesting problem given that if there are many poor herders and few rich herders, as would seem likely, the total number of livestock owned by the poor may outnumber those owned by the rich, yet any one poor individual still owns few. However, analyzing how such a herder should behave is somewhat more complicated in that we need to consider not only what he or she should do if $n-$ I or $n-2$ other players defect but also how many of these defectors are rich and how many are poor. We do so by supposing that there are a total of $p$ poor herders in the village and a total of $r$ rich herders. Of these, $q$ poor herders defect and $s$ rich herders defect. Given these numbers of other defectors, a poor herder who decides to cooperate should receive a payoff of

$$
\alpha f D+f /(r m+p f)^{*}(A-q \alpha f D-s \alpha m D)-C,
$$

while a defecting poor herder should receive

$$
\alpha f D+f /(r m+p f)^{*}[A-(q+1) \alpha f D-s \alpha m D] .
$$

A similar logic can be applied to obtain the payoffs for a rich herder. It can be seen that these equations reduce to the two-person game when $p=r=\mathrm{I}$ and $q=s=\mathrm{O}$ or I.

\section{RESULTS}

We determine which strategies provide the highest payoffs by comparing the expected payoffs of each strategy given which strategy was chosen by the other herder. Thus a poor herder should prefer to cooperate when a rich herder cooperates if $f(p c \mid r c)>f(p d \mid r c)$. Beginning with an analysis of the two-person game for the sake of simplicity, that occurs when

$$
\alpha f D+A^{*} f\left((f+m)-C>\alpha f D+(A-\alpha f D)^{*} f /(f+m),\right.
$$

which reduces to

$$
\alpha f D^{*} f /(f+m)>C .
$$

Thus, the poor herder should cooperate if the cost of going to the wet-season pastures is less than the amount of reduction of the available dry-season forage that would result from his "stealing" it during the wet season by defecting.

If a rich herder defects, then a poor herder should cooperate when $f(p c \mid r d)>f(p d \mid r d)$, that is, when

$$
\alpha f D-C>(\alpha m D)^{*} f /(f+m),
$$

in other words, when the amount taken from a distant pasture minus the cost of going there is greater than the poor herder's share of what the rich herder would "steal" from the nearby pasture while the poor herder was away.

In this particular case, inequalities 7 and 8 are identical. Thus, we find that the poor herder should cooperate no matter what a rich herder does whenever

$$
\alpha f D^{*} f((f+m)>C
$$

A rich herder faced with a cooperating or defecting poor herder should base his decision on the same criteria: cooperate when $f(r c \mid p c)>f(r d \mid p c)$ and $f(r c \mid p d)>$ $f(r d \mid p d)$. However, because rich and poor herders own differing numbers of livestock, payoffs are not identical, and thus their preferred strategies may sometimes differ. By a logic similar to that above, it can be shown that a rich herder should cooperate regardless of what the poor herder does when

$$
\alpha m D^{*} m /(f+m)>C
$$

It is possible to graph a set of evolutionary stable strategy (ESS) spaces by setting the left-hand side of inequalities 9 and ro equal to $C$ and then plotting each indifference equation against the proportion of poor herders' cows to rich herders' cows $(f / m)$. In the region above a curve, costs are higher than the level specified by that equation and cooperation is not preferred. Thus, above equation 9 defection is the best strategy for a poor herder, and above equation Io defection is the best strategy for a rich herder. In figure 2 there are three ESS spaces. Above both curves the ESS is "mutual defection"; both poor and rich should defect. Below both curves it is to the advantage of both parties to cooperate and there is no temptation to defect. The ESS is thus "mutual cooperation" (this could also be called "by-product mutualism" [Connor I995, Dugatkin I997]). In the regions between the curves, the ESS is "rich cooperate/poor defect." A similar pattern of results is obtained when the cost of moving is assessed on a per-animal basis rather than per capita - that is, when $C$ is multiplied by $f$ or $m$ for poor and rich herders, respectively-but the threshold for defection occurs at much lower values of $C$.

When the game is extended to $n$ players, we find that a poor herder should prefer to cooperate when

$$
\alpha f D^{*} f /(r m+p f)>C,
$$

and a rich herder should prefer to cooperate when

$$
\alpha m D^{*} m /(r m+p f)>C .
$$

These results are almost identical to those from the twoperson game ( 9 and ro) except that the denominator of the left-hand side is now $r m+p f$ rather than $m+f$ (fig. 
$\mathbf{a}$

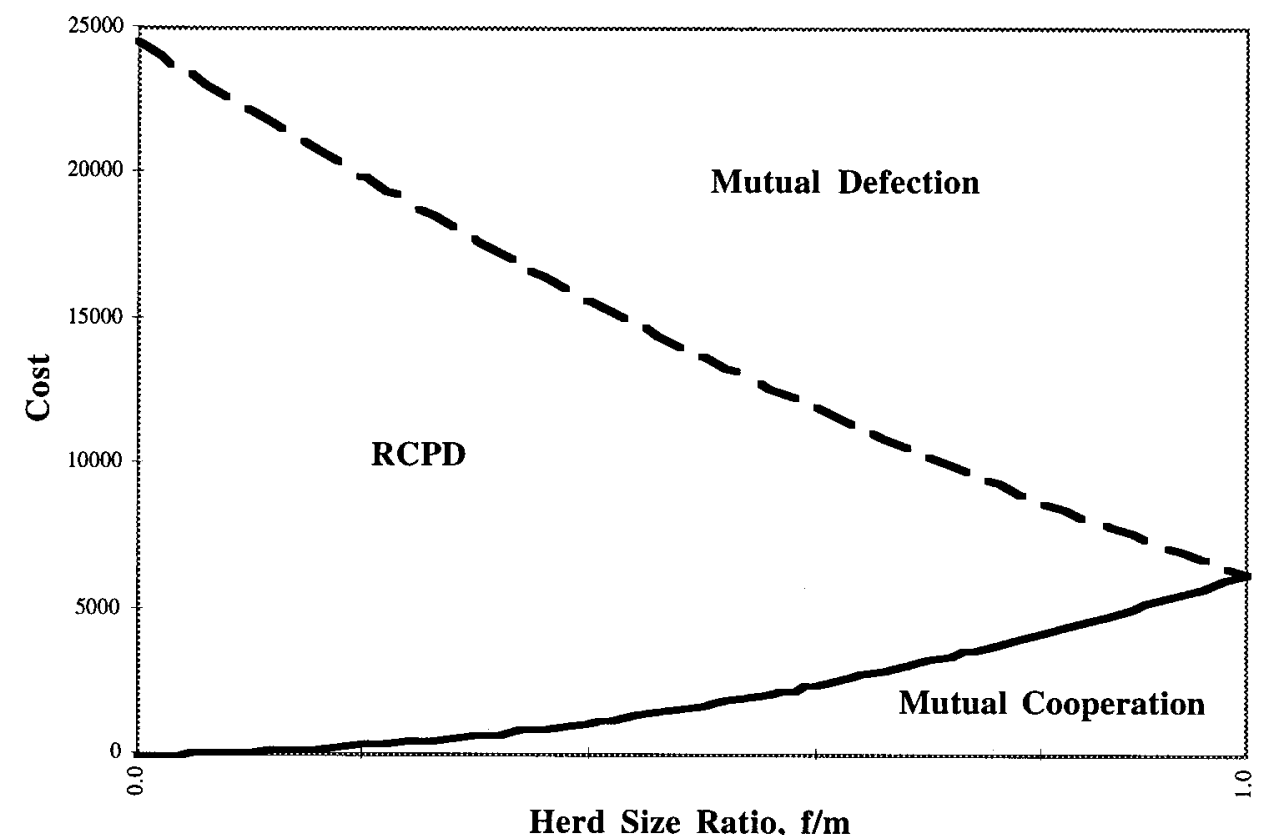

b

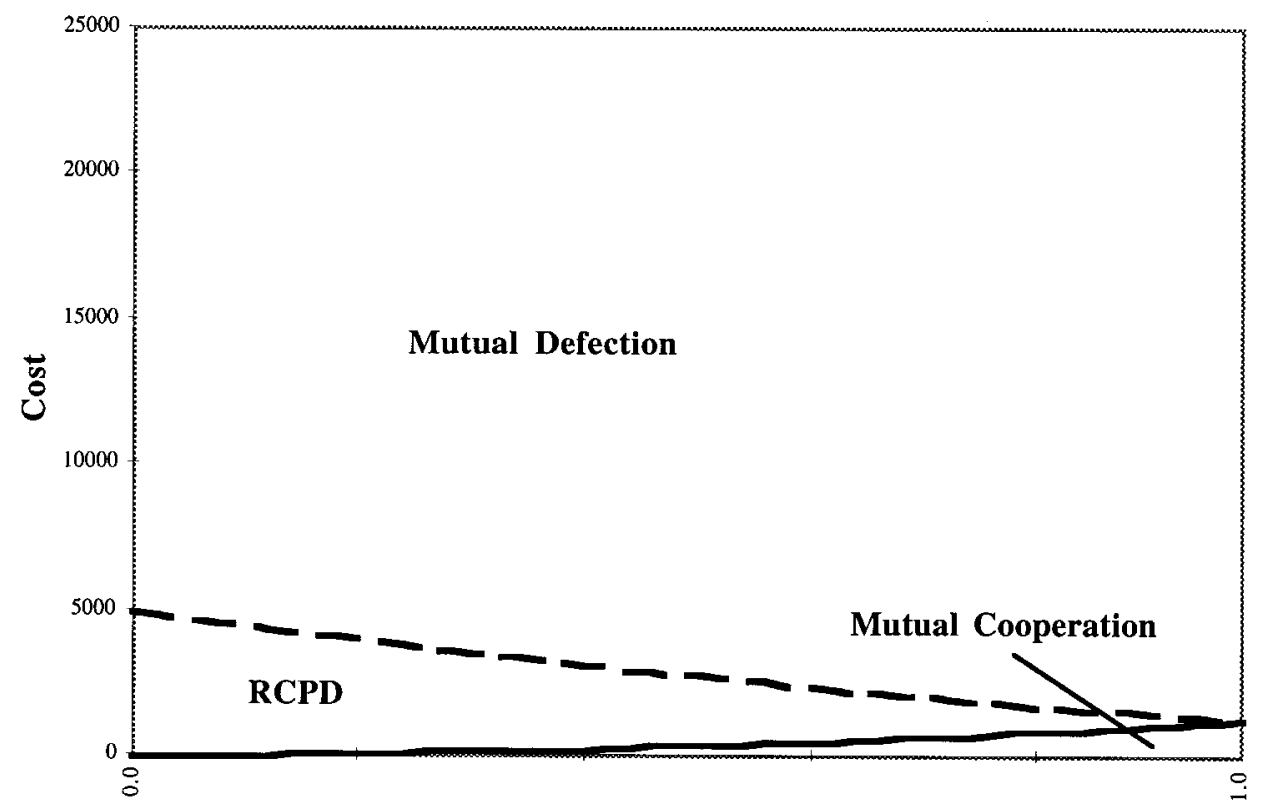

Herd Size Ratio, f/m

FIG. 2. ESS regions for a two-person game, plotted as a function of cost of moving to the wet-season pastures against the ratio of the number of livestock owned by poor herders to that owned by rich herders, $\mathrm{f} / \mathrm{m}$. Units of forage eaten per cattle per day, $\alpha$, is set at I. The lower curve in each graph is a plot of $f(\mathrm{pc} \mid \mathrm{rc})=f(\mathrm{pd} \mid \mathrm{rc})($ and $f[\mathrm{pc} \mid \mathrm{rd}]=f[\mathrm{pd} \mid \mathrm{rd}])$. Poor herders should defect above this curve. The upper curve plots the equation $f(\mathrm{rc} \mid \mathrm{pc})=$ $f(\mathrm{rd} \mid \mathrm{pc})$ (and $f[\mathrm{rc} \mid \mathrm{pd}]=f[\mathrm{rd} \mid \mathrm{pd}])$. Rich herders should defect above this curve (as do poor herders). In the region between the curves the rich should cooperate and the poor defect (RCPD). Total number of days that the wetseason pastures are available, $\mathrm{D}$, is 250 for graph a and 50 for graph $\mathrm{b}$. 
3). The implication is that both $m$ and $f$ are smaller relative to total village herd size $(r m+p f)$ and thus the lefthand side will tend to be smaller than in the two-person game.

Three clear patterns emerge from the two-person game, all of which make intuitive sense and suggest that the model captures many of the main features of grazing patterns among groups like the Barabaig. First, cooperation by either herder is precluded when the cost of using the wet-season pastures is very high (perhaps these seasonally available pastures are very remote, or perhaps construction and defense of the wet-season camps engages the labor of many young people in the household). This is particularly the case when the wet-season pastures are available only for a short time (fig. $2, b)$. Second, mutual cooperation is most likely when wealth inequalities are mild and costs are low, that is, when the payoffs to any given strategy are somewhat similar for wealthy and poor herders. Third, unilateral cooperation on the part of the rich is most common when the costs of using the wet-season pastures are moderately high and the inequalities in wealth are sharp and thus only some individuals are in a position to benefit from the pastures.

The patterns observed in an $n$-person game are similar; the rich are always more likely to conserve than the poor, since their herds are relatively large compared with poor individuals'. However, as the herd size of any one individual, rich or poor, declines relative to the village's combined herd size, that individual is more and more likely to defect; in other words, he will conserve only if the costs of moving to the wet-season pastures are much smaller than in the two-person game. Although mutual cooperation is much less likely, given that a poor individual's relative herd size rapidly declines with increasing numbers of people in the village, unilateral cooperation on the part of the rich remains likely if there are large asymmetries in wealth and only a few rich individuals (fig. 3, $b$ ).

Two of the more general results of these models are directly relevant to the question of how to identify and account for conservation acts. First, under many of the conditions we have modeled, respect for dry-season reserves emerged as a stable strategy. In other words, conservation occurred for purely selfish economic reasons and is therefore isomorphic with economic efficiency. Second, because of the asymmetrical payoffs contingent on the differing numbers of livestock owned by the two players, herders have different thresholds for triggering defection, which leads to the unusual outcome of rich cooperate/poor defect. Again, there is no problem requiring policing or assurances of cooperation. These are interesting theoretical results, but with respect to the Barabaig there is one aspect of the ethnography that remains inconsistent with the analysis. The Barabaig fine individuals who do not respect the dry-season reserves. If conservation were always consistent with individual preferences there would be no need for fines. There are two principal explanations for this. First, the mutual defection ESS may be masking a prisoner's dilemma game. Second, although rich cooperate/poor defect is stable, the rich might be even better off if they could coerce the poor into cooperating.

When the costs of using the wet-season pastures are high and herd sizes are relatively equal, mutual defection is the ESS in a one-shot two-person game. However, if in fact all individuals would be better off if all cooperated rather than if all defected, we have a prisoner's dilemma; in our case this would occur if $f(p c \mid r c)>f(p d \mid r d)$ and $f(r c \mid p c)>f(r d \mid p d)$. (Note that we do not have an assurance problem, that is, that there is only one ESS, mutual defection.) We find that $f(p c \mid r c)>f(p d \mid r d)$ when

$$
\alpha f D+A(f / f+m)-C>A(f / f+m),
$$

which reduces to

$$
\alpha f D>C \text {. }
$$

Similarly, $f(r c \mid p c)>f(r d \mid p d)$ when

$$
\alpha m D>C \text {. }
$$

When equations I 3 and I 4 are plotted on the same graph as equations 9 and Io, we find there are now six different subspaces (still with three one-shot ESS's) (fig. 4). Arrow diagrams for each of these regions are presented in figure 5. The ESS in region A is mutual cooperation. Regions $\mathrm{B}_{1}$ and $\mathrm{B}_{2}$ are both forms of rich cooperate/poor defect. Region C, however, has three different subspaces. In area $\mathrm{C}_{3}$, we have true mutual defection, where all parties are really best off defecting. In area $\mathrm{C}_{\mathrm{I}}$, there is a clear prisoner's dilemma. If individuals can find a way of preventing free-riding, as seems reasonable for villagers who interact repeatedly, they are better off all cooperating than all defecting. Finally, in region $\mathrm{C}_{2}$, only the rich would be better off if all cooperated than if all defected. The poor would in fact be better off if all defected than if all cooperated. We label this the "rich prisoner's dilemma." Here, it is not sufficient simply to resolve a collective-action problem through agreed-upon punishment, since only rich individuals experience a prisoner's dilemma. Thus, cooperation by all could only be the result of coercion of the poor by the rich.

Coercing the poor into conserving resources may also be profitable for the rich when the ESS is rich cooperate/ poor defect (but not in the BI zone, where the rich are really best off letting the poor defect). If we return to considering a two-person game for the sake of simplicity and adopt the approach of Clutton-Brock and Parker $($ I $995 a, b)$, we now allow play to continue for $N$ rounds. As before, rich and poor herders have two choices of strategy, but now the rich herder may cooperate and punish or cooperate and not punish. (We ignore the choice of defecting, since we are restricting ourselves to considering a game played under the parameter values that led to a rich cooperate/poor defect strategy in the first place, and thus defecting is not an option for the rich.) If the rich herder chooses to punish, a fine of $t$ is imposed 
a

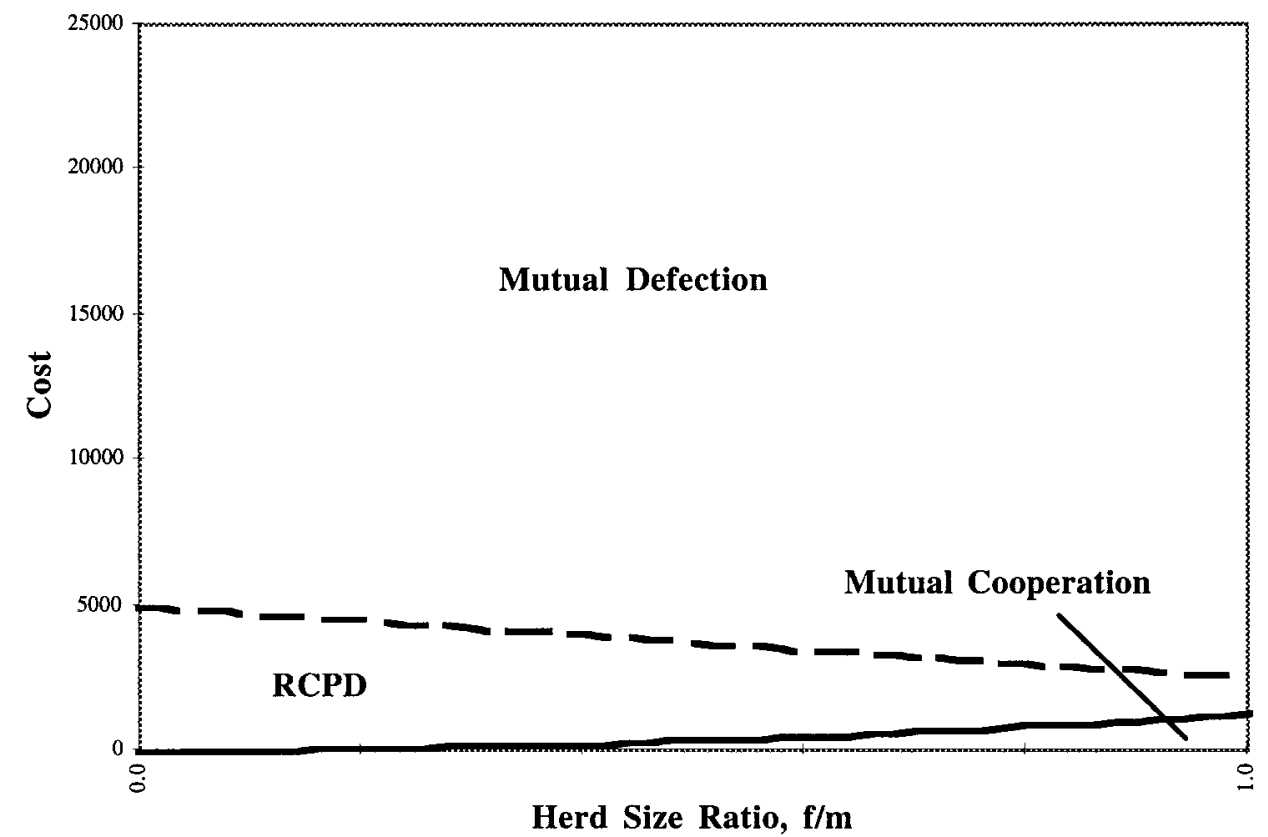

b

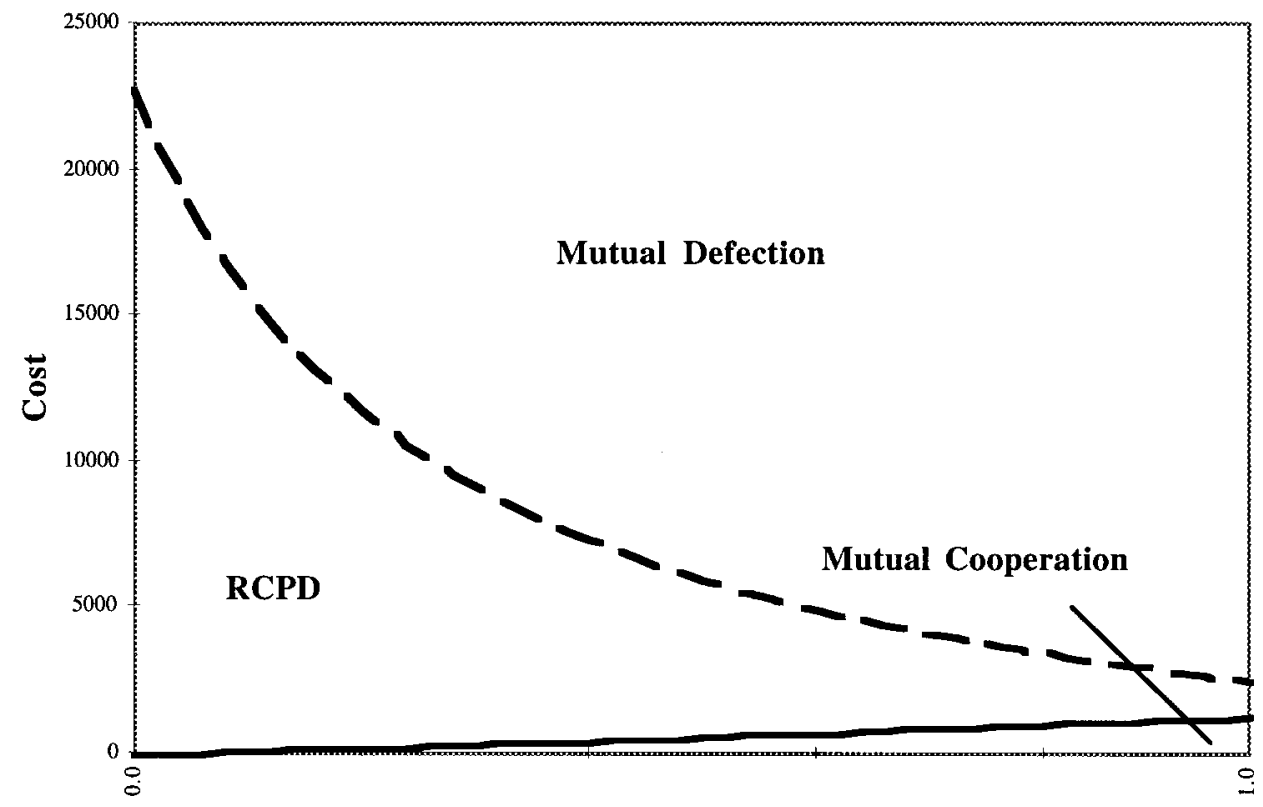

Herd Size Ratio, f/m

FIG. 3. ESS regions for a n-person game, plotted as a function of cost of moving to the wet-season pastures against the ratio of the number of livestock owned by poor herders to that owned by rich herders, $\mathrm{f} / \mathrm{m}$. Total number of days the wet-season pastures are available, $\mathrm{D}$, is 250 , and units of forage eaten per cattle per day, $\alpha$, is set at I. The upper curve shows the equation $f(\mathrm{rc} \mid \mathrm{pc})=f(\mathrm{rd} \mid \mathrm{pc})$ (and $f[\mathrm{rc} \mid \mathrm{pd}]=f[\mathrm{rd} \mid \mathrm{pd}]$ ), and the lower curve shows the equation $f(\mathrm{pc} \mid \mathrm{rc})=f(\mathrm{pd} \mid \mathrm{rc})$ (and $f[\mathrm{pc} \mid \mathrm{rd}]=f[\mathrm{pd} \mid \mathrm{rd}])$. Numbers of poor and rich herders are as follows: graph $\mathrm{a}, \mathrm{p}=\mathrm{r}=5$; graph $\mathrm{b}, \mathrm{p}=9, \mathrm{r}=I$. 


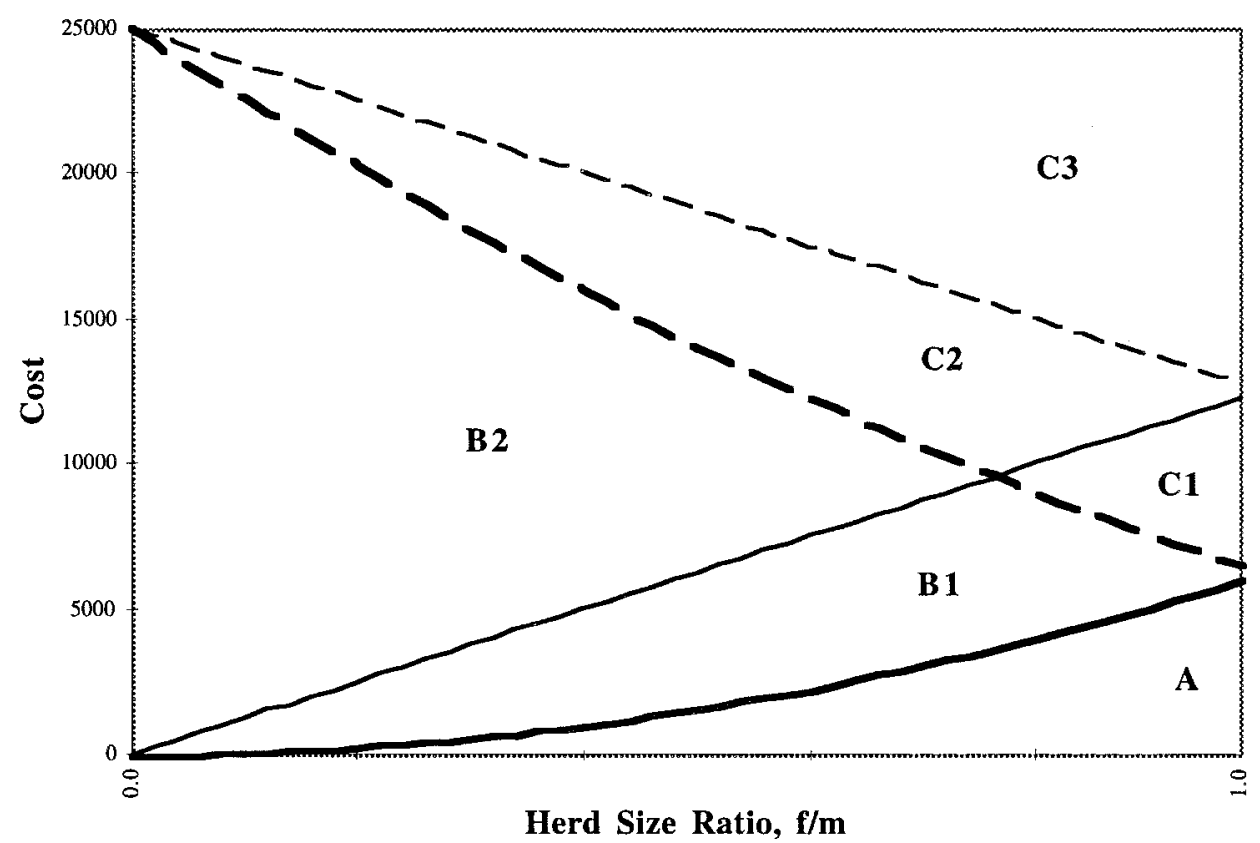

FIG. 4. ESS regions and subspaces for a two-person game. Equations I3 $(f[\mathrm{pc} \mid \mathrm{rc}]=f[\mathrm{pd} \mid \mathrm{rd}])$ and I4 $(f[\mathrm{rc} \mid \mathrm{pc}]=$ $f[\mathrm{rd} \mid \mathrm{pd}])$ are overlaid on figure 2, a. The subspace ESS's are A, mutual cooperation; $\mathrm{B}$, RCPD-I; $\mathrm{B} 2, R C P D-2$; $\mathrm{C}_{\mathrm{I}}$, prisoner's dilemma; $\mathrm{C}_{2}$, rich prisoner's dilemma; $\mathrm{C}_{3}$, mutual defection.

on the poor herder while the rich herder receives $t-i$, where $i$ is the cost of imposing this fine. The poor herder has the choice of continuing to defect or cooperating conditionally, that is, cooperating only after having been punished for defecting. A conditional cooperator experiences punishment for $j$ rounds before deciding to cooperate in the remaining $k=N-j$ rounds. The payoff matrix for this game is illustrated in figure 6 . The poor herder should prefer conditional cooperation to defection if

$$
j[f(p d \mid r c)-t]+k^{*} f(p c \mid r c)>N[f(p d \mid r c)-t],
$$

which reduces to

$$
t>f(p d \mid r c)-f(p c \mid r c)
$$

that is, if the punishment is greater than the difference between what is gained from defecting and what is gained from cooperating. Substituting the full equations for $f(p d \mid r c)$ and $f(p c \mid r c)$, we have

$$
\begin{gathered}
t>\left[\alpha f D+(A-\alpha f D)^{*} f /(f+m)\right] \\
-\left[\alpha f D+A^{*} f /(f+m)-C\right],
\end{gathered}
$$

which reduces to

$$
t>C-(\alpha f D)^{*} f /(f+m) .
$$

Thus, poor individuals are better off cooperating when the fine is greater than the difference between the cost of going to the wet-season pastures and the amount they could have "stolen" from the dry-season reserves had they defected. Otherwise, they should continue to defect even though they are punished.

Since we have assumed a rich cooperate/poor defect strategy, we know that rich herders are always better off cooperating and not punishing as opposed to defecting and not punishing. Is it worthwhile, however, for the rich to cooperate and punish? If a poor herder defects, the rich herder is better off punishing when

$$
N^{*}[f(r c \mid p d)+t-i]>N^{*} f(r c \mid p d),
$$

that is, when

$$
t-i>0 \text {. }
$$

If the poor herder conditionally cooperates, then it pays the rich herder to punish when

$$
j[f(r c \mid p d)+t-i]+k^{*} f(r c \mid p c)>N^{*} f(r c \mid p d),
$$

which reduces to

$$
j^{*}(t-i)+k^{*} \alpha f D^{*}(m / f+m)>0 .
$$

The rich herder benefits when the net fines gained from coercing the poor each time he defects plus the rich herder's share of what the poor herder would have "sto- 


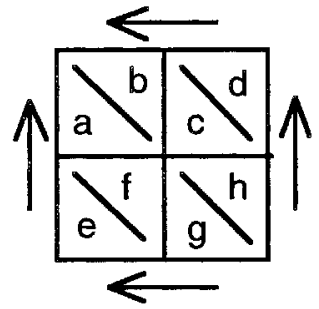

A. Mutual Cooperation $a>g, b>h$

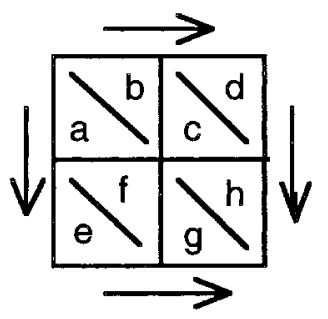

C1. Prisoner's Dilemma $a>g, b>h$

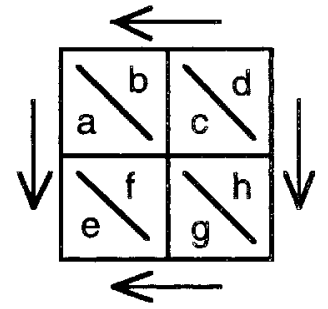

B1. RCPD 1 $a<g, b>h$

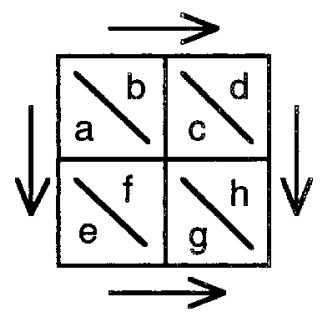

C2. Rich PD $a<g, b>h$

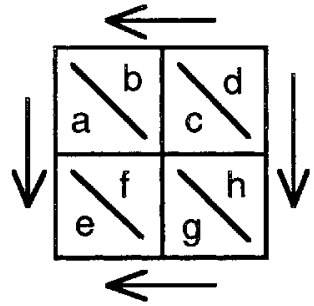

B2. RCPD 2 $a>g, b>h$

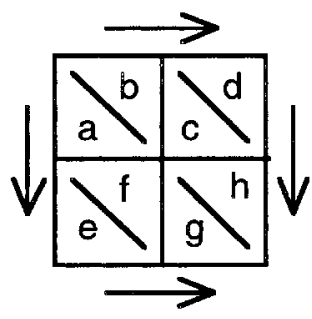

C3. Mutual Defection $a<g, b<h$

Fig. 5. Payoff preferences in the six regions from figure 4. Horizontal arrows point to higher payoffs in row comparisons, vertical arrows to higher payoffs in column comparisons. Diagonal comparisons of payoffs to mutual cooperation and mutual defection are indicated below boxes.

len" from the dry-season reserves each time are greater than zero. Since the second term on the left-hand side is always greater than zero, this inequality holds as long as $t>i$ or, if not, then as long as the second term is larger than the first. The latter will be the case when the poor's herd size is large. Otherwise, the rich herder may not be better off punishing even if the poor herder continues to defect. There can also be an ESS in which the poor herder prefers to defect and the rich herder prefers to punish. That can occur if $t>i$ and $t<f(p d \mid r c)-f(p c \mid r c)$.

In summary, mutual cooperation is, in theory, possible. By this we mean that all individuals may find it in their own best interest to move cattle to the wet-season pastures during the rainy season, thereby conserving the dry-season reserves. We do not claim to have resolved the second-order problem of cooperation if there were to be more than one punisher, as in an $n$-person game. We do know, however, that in the case of the Barabaig the existence of fines suggests that at least for some herders, perhaps only in some years, defection is the preferred strategy. We do not know whether what we observe reflects a prisoner's dilemma, a rich prisoner's dilemma, or a rich cooperate/poor defect strategy in which the rich coerce the poor to cooperate. Thus, we ask what opportunity there is for such coercion among the Barabaig.
SOME SPECULATIONS ON COERCION AND POLICING

Among pastoralists, the herd owners who benefit the most from conservation of the dry-season reserves (i.e., those with the largest herds) are commonly those who are the most powerful in their local communities as elders. Though wealth is not a prerequisite for elder status, influential and respected elders are usually rich in livestock, at least among other pastoralists in this region. Furthermore, elders are in a good position to enforce grazing rules and to sanction and punish violators of these rules precisely because they are the principal owners of coveted livestock wealth. Ethnographic references point to their role in enforcing grazing regulations and policing infractions (through committees and moots) with the help of younger kinsmen who stand to inherit their wealth (e.g., Lane I996; see also Borgerhoff Mulder I988). As our analysis shows, it is to their advantage to do so given certain parameter conditions-those that produce a rich cooperate/poor defect strategy and involve a fine greater than the cost of collecting it.

That coercion is advantageous to the rich seems to be the case for the Barabaig. First, in such a system the costs of detecting cheaters are small. Given the proximity of the dry-season reserves to permanent homesteads, cattle cannot be grazed there illegally in the dry season without 


\begin{tabular}{|c|c|c|}
\hline & Rich Cooperates \& Punishes & Rich Cooperates \& Doesn't Punish \\
\hline $\begin{array}{c}\text { Poor } \\
\text { Cooperates }\end{array}$ & $\begin{array}{l}\mathrm{j}^{*}[f(\mathrm{rc} \mid \mathrm{pd})+\mathrm{t}-\mathrm{i}]+\mathrm{k}^{*} f(\mathrm{rc} \mid \mathrm{pc}) \\
\mathrm{j}^{*}[f(\mathrm{pd} \mid \mathrm{rc})-\mathrm{t}]+\mathrm{k}^{*} f(\mathrm{pc} \mid \mathrm{rc})\end{array}$ & $\mathrm{N}^{*} f(\mathrm{rclpd})$ \\
\hline $\begin{array}{l}\text { Poor } \\
\text { Defects }\end{array}$ & $\begin{array}{l}\mathrm{N}^{*}[f(\mathrm{rclpd})+\mathrm{t}-\mathrm{i}] \\
\mathrm{N} *[f(\mathrm{pdlrc})-\mathrm{t}]\end{array}$ & 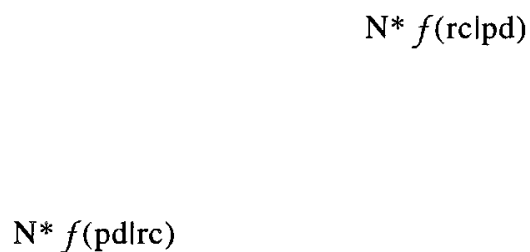 \\
\hline
\end{tabular}

Fig. 6. Payoff matrix for a game between two herders, one rich and one poor, where the rich herder has the choice of cooperating and punishing or cooperating and not punishing. The poor herder can either defect or cooperate conditionally if punished. Payoffs to the poor herder are in the lower left corner of each cell while payoffs to the rich herder are in the upper right.

being spotted. (By contrast, in the Eyasi Datoga, where the critical dry-season grazing is far from the main area of settlement, cheaters are less easily detected; however, since their dry-season pastures are viewed as less nutritious than their wet-season pastures, cheating is less of an issue.) Second, the costs of bringing offenders to trial may be low. Men with moderate-sized herds, one or more wives, and grown sons are not usually directly involved in the herding of their stock and enjoy more leisure (e.g., Fratkin I989). In fact, in the Datoga and probably many other pastoral communities (Fratkin and Smith I994), wealthier men have more people living in their homesteads (Sieff I997). There are therefore few opportunity costs for wealthy old men in spending time on committees and councils, attending trials, and adjudicating moots. Third, when offenders are punished a fine is exacted; among the Datoga and many other groups, disputes can be resolved with fines of cattle or with obligations to brew honey beer. In either case, the payment is consumed by the elders on the relevant councills) (Klima I965), even where women adjudicate (Klima I964). Finally, in the Barabaig (Lane I996) and several other groups, it is reported that some councils operate in total secrecy; this could protect the members from the possible retribution of those who are punished. Each of these considerations serves to reduce the costs associated with punishment and regulation and to increase the benefits received by individual punishers.

All of these conditions would also serve to enforce cooperation through reciprocity if they were not in the region of the rich cooperate/poor defect strategy but in a prisoner's dilemma. Further empirical research is needed to determine where the Barabaig and other pastoral groups would fall in figure 5 .

\section{FUTURE DIRECTIONS IN MODELING}

As with any model, a number of simplifications have been made, two of which are particularly critical. First, we have not considered the second-order problem of cooperation-the question of who polices the police. However, our aim is to show that conservationist behavior, in this case moving cattle, can be self-interested. Secondly, we have not considered what happens when the dry-season reserves are exhausted before the rains return, in which case cattle can die or pastures may be permanently degraded. One might suspect that cattle loss would be more costly for poor than for rich herders on account of their greater exposure to starvation; this suspicion is supported by the observation that poor herders keep a higher proportion of their livestock alive during droughts than rich herders (e.g., Herren I990, Fratkin and Roth I990). If the poor are more averse to losing cattle, this could lower their threshold for cooperating (and make them more likely to conserve). Conversely, with regard to range quality, it might be that rich herders discount future payoffs at a lower rate than poor herders; this notion arises from the observation that in many populations (e.g., Bradburd I982, Fratkin and Roth I990, Sieff I995) poor families are much more likely to drop out of pastoral production than are rich families or at least to diversify production with honey collection, hunting, and cultivation. In addition, the cost of using wet-season pastures can also vary according to the wealth of the herder, since poorer families often have insufficient labor to maintain two households (Sperling and Galaty 1990, Borgerhoff Mulder and Sellen I994). However, we suspect that the overall picture would look the same, although actual values of costs would vary (as 
between figs. 2, $a$ and $2, b$ ), and the poor would be less likely to conserve. It is quite easy to imagine how each of these factors might affect the ESS outcomes, but careful modeling of these effects and their interactions will tell us more about when, where, and why we might expect people to adopt conservationist strategies with respect to the management of their critical pastoral resources. Even more important, the model can be made more realistic with respect to the diversity of land use patterns observed among African pastoralists by varying the costs of mobility, the relative productivity of wetand dry-season pastures, and the ease of detecting cheaters.

\section{Conclusions}

\section{GENERAL CONCLUSIONS}

Conservation can be an outcome of individuals' attempting to increase their own economic returns, or efficiency, and asymmetries in payoffs result in situations in which conservation can arise from unilateral cooperation and/ or coercion of the weak by the powerful.

The first of these conclusions may simply be a logical consequence of our decision to look for restraint in strategies that are aimed at long-term efficiency. However, it raises questions about the appropriateness of assuming that conservation is an alternative to economic maximization. Although it is clear why investigators such as Hames made this assumption, now that the hunt for conservation behavior is moving beyond the realm of prey choice in foragers it may be more productive to look for conservation acts within the framework of efficiency maximization. While we do not claim that the traditional conservation practices of the Barabaig correspond to mutual cooperation, we do wish to remind readers that not all interactions are structured as a prisoner's dilemma (or as an assurance game in which all-cooperate and all-defect are both ESS's). While many researchers recognize that conservation of privately owned resources can result from self-interested behavior (but see Clark I973 on the incentives to overharvest such resources), few have modeled how conservation of common pool resources may result from self-interested cooperation, focusing instead on the resolution of a collective-action problem, that is, a prisoner's dilemma (but see Galaty I993). In our model, mutual cooperation is most likely to occur when heterogeneity among players and costs of conservation are low. It is notable that many institutional economists and political scientists have observed that low levels of heterogeneity characterize most successful instances of the collective management of common pool resources (e.g., Ostrom I990, Hanna, Folke, and Maler 1996).

As the costs of conservation and the degree of asymmetry in payoffs increase, opportunities for unilateral (if not mutual) conservation may emerge. If, in addition, asymmetries in payoffs map onto asymmetries in power, dominant individuals may coerce all individuals into co- operating. Following Vehrencamp (I983), we assume that subordinate individuals lack outside opportunities which would allow them to evade coercion. While this model draws inspiration from work by Clutton-Brock and Parker (1995 $a, b$ ), earlier work on the effects of punishment also found it effective in generating cooperation (Boyd and Richerson I992a). Although few field studies have attempted to test these models, some social scientists have also argued that a certain amount of heterogeneity facilitates collective action insofar as members of a small, "privileged" group may find it individually advantageous to support the costs of collective action (Olson I 967, Bergstrom, Blome, and Varian I986, McKean I992, Ruttan I998). Although this apparent paradox may be the result of there being a U-shaped relationship between heterogeneity and the success of institutions for the management of common pool resources, it has been suggested that trying to predict the success or failure of these institutions on the basic of heterogeneity is too simplistic (Varughese and Ostrom I998).

Using game theory to explore the consequences of asymmetries in power and payoffs supplies some muchneeded political and economic reality to the study of conflicts over resources within and even between communities. Failure to place the study of conservation more squarely within a politico-economic context was one of the main criticisms of earlier studies of conservation in indigenous groups. One of the few exceptions to a general neglect of games with asymmetrical payoffs is Ostrom, Walker, and Gardner's (1994) analysis of the behavior of two irrigating farmers, one of whom is upstream and thus has the power to control resource flows and one who is downstream but has the ability to punish the former. However, their game differs from the one presented here in that the "dominant" individual, that is, the one who controls resource flows, is not the punisher. Thus, in their game, asymmetries do not lead to voluntary cooperation. In the pastoralist case, the people with the most power are also those most interested in conservation. This may be an important reason that pastoralists often seem to be successful in protecting their commons from degradation, at least where these systems are unperturbed by external forces. For this reason, we believe that the pastoralist case is particularly appropriate for investigating this problem.

DOES CONSERVATION POSE A COLleCtive-ACTION PROBLEM IN PASTORALISTS?

One might wonder to what extent the Barabaig system is representative of pastoralism in general. Barabaig's land use is somewhat unusual in that they preserve nearby dry-season pastures for later use whereas the commoner pattern among pastoralists is to move away from their more permanent bases in order to locate forage at distant dry-season pastures. This is not an insignificant difference. Precisely because preservation of nearby and easily accessible grazing is at issue, we would be more likely to expect a collective-action dilemma among 
the Barabaig than among other groups, for whom there is less temptation to use dry-season resources out of season or out of turn. In these latter cases, it is more obvious that foraging decisions are made on the basis of efficiency maximization and hence any conservation is fortuitous or even epiphenomenal. For example, Dyson-Hudson and Dyson-Hudson (1969) argue that the Karamojong use resources as they become available and that dry-season pastures are not set apart for use at a later time. Legesse (I973) suggests that it is the controlled access by certain families to key water sources that prevents overgrazing by the Boran. In the case of the Turkana, well-described by McCabe (1990), and other cases (e.g., Sieff I 997), dryseason pastures have higher primary productivity than wet-season pastures (McCabe I997), but it is unclear whether there would in fact be a short-term advantage to "stealing" dry-season grass, since these pastures are very far away from settlements (although there might be some temptation to go there earlier than others). Returning to the Barabaig, there is some suggestion that forage in the wet-season pastures is better than that in the dry-season reserves but it is far away (Lane I996). Thus, it is not clear whether wet-season graze is more profitable than nearby dry-season forage. For this reason one would expect that individuals do, in fact, face a difficult decision in choosing whether to move to the wetseason pastures or not. These reasons justify our analysis of this case as a problem of cooperation. ${ }^{6}$ How general it is is hard to determine.

Given the evidence, it would be difficult to reject the hypothesis that conservation outcomes observed among pastoralists are largely the epiphenomenal consequence of high mobility, low population, dispersed water sources, disease avoidance, and security issues. The fact that grazing regulations exist and moots sit to punish violators suggests, however, that infractions do occur. This suggests that although protecting grazing reserves may be a strategy that makes long-term economic sense, it may not be in the short-term interest of all individuals. Hence, conflicts of interest will arise either because conservation is in the long-term best interest of individuals but there is a collective-action problem (i.e., payoffs are structured as in a prisoner's dilemma) or because some individuals are being coerced into conserving resources when it is not in their own best interest.

\section{PASTORALISM AND SELF-INTEREST}

It is now largely accepted that pastoralism is a poor example of a tragedy of the commons. Two of Hardin's (I968) assumptions-that access to the commons can be characterized as a free-for-all and that herders are motivated only by immediate self-interest-are frequently challenged. It is clear that pastoral commons are not

6. We do not restrict the definition of cooperation to cases in which there is a collective-action problem (see also Dugatkin I997). In our case, individuals cooperate by refraining from grazing in the dry-season reserves early on, and thus each individual contributes to the total amount of the common pool resource that is available later during the dry season. open-access (Ciriacy-Wantrup and Bishop I975); regulated use by community members and exclusion of nonmembers are integral to known pastoral land use systems in Africa and elsewhere (e.g., Netting 1976). Furthermore, where commons are degraded, it is often because of external interventions (e.g., Hogg I990, Ensminger and Knight I997) that cause a breakdown of the communal management system. Hardin's second assumption, that individuals are narrowly self-interested, is not popular in the social sciences and certainly not popular among scholars of pastoralism (e.g., Peters 1987, Lane 1996). These scholars argue from observation that narrow selfinterest is in practice kept in check by a variety of social norms and institutions. Furthermore, some scholars propose that the use of common pool resources is more frequently characterized by an assurance problem (Sen I967) than by a free-rider problem, largely because villagers are interdependent (Runge I98I, I984). Either traditions lead individuals to expect that others will also cooperate (thus rendering stinting the most advantageous strategy for the individual) or, as Hyden (I990) notes, individuals will be predisposed to avoid sanctions from neighbors on whom they are completely dependent (some evolutionary thinkers are adopting the same argument [e.g., Tooby and Cosmides I996]).

As evolutionary ecologists, however, we wish to explain both the emergence and the persistence of collective action-that is, how such institutions and/or social norms may have originated and why particular institutions evolved rather than others. In this spirit, conformity with social norms is taken not as evidence against self-interest but rather as reason to question how long-term self-interest might be favored by such norms and how short-term self-interest is subverted in favor of long-term self- (and possibly group) interest. (Construed thus, a large part of the disagreement is obviously a definitional issue of what constitutes self-interest.) There are many studies addressing the latter issue. Edney and Harper's (I978) work showed that initial communication among players prior to the game helps markedly to encourage cooperation and therefore to avoid the defections that generate commons abuse. More recent work by Ostrom, Walker, and Gardner (1992, I994) also emphasizes the critical role of communication in facilitating cooperation as well as demonstrating the importance of moderated sanctioning behavior. These and many other experimental studies of cooperative behavior essentially take the approach that even if individuals are fundamentally self-interested, they may lack perfect information-that is, they simply may not know what the outcomes of different strategies would be and/or lack the cognitive abilities needed to calculate the outcomes of a very large set of possible actions. For this reason, rules of thumb may have evolved which, on average, favor the individual over the long term. Along these same lines, Simon (I990) offers a more general argument that docility-meaning receptivity to social influence (and presumably social institutions)-is likely to have been selected in our species; this docility may underlie the 
conformity and altruism seen in common property institutions.

In the case of pastoralists, if we accept "broad" selfinterest but question the assumption of perfect rationality, there are other plausible hypotheses for collective action that should be considered. First, there is the possibility that cooperation arises out of imitation. McCabe (I997) makes the interesting observation that herders often follow the grazing decisions of successful individuals in their communities; by this means they might all converge on a grazing pattern best suited to the more prosperous (imitated) herder. According to this argument, imitation of a focal figure might account for cooperation. Second, there is the possibility that cooperation arises from a game of coordination. Galaty (I994) proposes that the opening of dry-season pastures is often determined consensually and enforced by community sanctions; this process of "coordination access" (I994:I87) entails the effective rationalization of herd movement through progressive adjustments made by herders in response to each other's needs and movements. Similarly, McCabe (I 997) points to the potentially important role of prophets in coordinating group movement (see also Lansing I 988 on irrigation agriculture).? Each of these two ideas is consistent with Boyd and Richerson's (I985) discussion of how cooperation might arise through the mechanisms of cultural evolution.

We retain a paradigm based on individual self-interest on the assumption that it is self-interest itself that generates the complex web of interdependencies among households within a community (Borgerhoff Mulder and Sellen I994). First, men rely for survival and family persistence on a common set of resources, water and land; their fates are therefore inevitably intertwined through both cooperation and competition. Second, poorer families (or households) value the presence of wealthier families in their neighborhood, since the latter not only commonly provide community defense (of land and stock) but also offer quasi-patronage to households with insufficient livestock for subsistence (e.g., Borgerhoff Mulder I99I). Third, rich families benefit immensely from the labor provided by poor families (Fratkin and Smith I994, Sieff I 995). Fourth, as documented in almost every pastoral ethnography, numerous mechanisms exist whereby a household undergoing crisis receives gifts or loans of livestock, mechanisms that could be interpreted as providing insurance against risk over periods of years. In short, members of pastoral communities are highly interdependent though by no means necessarily equal in wealth (Borgerhoff Mulder I991, I 999). These dense networks of rights and obligations have quite understand-

\footnotetext{
7. In considering the distribution of water among farming villages (subaks) in Bali, Lansing (I988) proposes that cooperation arises as a result of farmers' converging on a particular distributional pattern which is advantageous to all. They do this, he argues, by responding rationally to incentives and copying neighbors who do better than themselves; thus no coercion is implied. Lansing's argument is intriguing but is probably not generalizable beyond the very specific conditions of Indonesian irrigated agriculture, where flooding must be done simultaneously or everyone suffers from pests.
}

ably distracted the attention of pastoral ethnographers from individual self-interest (since self-interest is not readily apparent) and stimulated analysts to caution against the use of a paradigm that separates individuals from the social, political, and economic structures in which they live (Peters 1987:193). Self-interest may, however, lie at the root of these highly interdependent communities.

\section{A FRIENDLY AMENDMENT TO THE CURRENT DEFINITION OF CONSERVATION}

Our definition of conservation as actions that "are intended to and do in fact prevent or at least mitigate resource depletion, species extinction, or habitat degradation" (Smith I 995:8 Io) highlights five criteria:

I. The act must be costly, at least in the short run; cost, however, is a necessary but not sufficient criterion (Alvard I995:8I4).

2. The act must be the true cause of the conservation outcome. In other words, the behavior must be shown to be well designed for the task of conservation, as is the case with identifying any behavioral adaptation (sensu Williams 1966). As noted by Hunn (I982), it must be abundantly clear that resource protection is not the result of some other factor, such as low population density or high mobility. Such incidental outcomes Hunn calls "epiphenomenal conservation." Examples include conservation that occurs in warfare-delineated buffer zones (Hunn I982, McCabe I990) and sustainable hunting by humans living at low population densities (Vickers I99I).

3. The act must have the demonstrable effect of conserving the resource. Whereas Hunn (I982) was objecting to the misidentification of causes, here we object to the mislabeling of outcomes. Often an act is claimed by an actor or ethnographer to have a conservation effect without conclusive evidence of that effect over time (Acheson and Wilson I996).

4. There must be some mechanism whereby the act is maintained in the population-most plausibly the operation of natural selection on genetic or cultural traits. Thus the act must be immune to invasion by other (nonconservationist) variants.

5. The act must be intended. Although it is unclear how affirmation by the actor that the act is intended to ensure conservation tells us anything about design, it may be extremely useful in development hypotheses to test in the field.

These criteria have been debated more or less explicitly in the commentary on Alvard (I995). Our contribution is to clarify requirement 2 , that an act is conservation only if it is not "epiphenomenal" in Hunn's (r982) sense. We wish to separate cases due to individuals' attending to their own long-term economic interests, which are epiphenomenal but fortuitous, from those that have other root causes such as low population densities and avoidance of warfare zones. Of course, efficiencymaximizing strategies do not always generate conservation; our model simply points to some conditions in 
which they do. These cases are particularly interesting in that we might expect them to be more likely to withstand changes in the economy. Our approach thus permits a study of fortuitous conservation in much the same way as we study arms races (or warfare), outcomes of other adaptive processes which are not generally treated as adaptations in themselves. It avoids the troublesome problem (Hill I 995) of having to distinguish conservation from efficiency when so often these are isomorphic. In short, while we respect the logical clarity of distinguishing between groups who apply conservation measures overtly to conserve resources from those whose various practices, beliefs, and rituals have the incidental effect of conservation, we suspect that identifying some conservation as epiphenomenal underestimates the significance and complexity of the processes entailed.

COMPARATIVE STUDY OF COMMON-PROPERTY

MANAGEMENT: PRACTICAL IMPLICATIONS

Where should applied anthropologists and development workers look for useful models of commons management? This is a question that grips social scientists charged with finding solutions to environmental problems (e.g., IIED I994, Alpert I996). Hunter-gatherers are unlikely to provide useful general models. This is primarily because they have few collective institutions whereby individual acts are regulated and punished. What conservation occurs in these systems is probably epiphenomenal, resulting from mobility and low population density. Too often external pressures (such as the intrusion of markets and/or immigrant populations in conjunction with new technologies) destabilize production systems that appeared to have been at equilibrium, precisely because many indigenous foraging groups have neither the institutions to prevent the free-for-all associated with open-access resources nor the political influence to protect their rights (e.g., Hames I99 I, Kaplan and Kopishke I992). This situation is nevertheless radically changing as indigenous people, often in alliance with external conservation agencies, obtain legal rights to their land.

If we look at stratified populations, we are more likely to find conservation in traditional contexts. In a thoughtful review of possible alternative explanations for cases of restraint, Gadgil and Berkes (I991:I35) point out examples in which regulations (such as those on the Pacific Fanafuti Atoll that render turtle meat taboo to all except the king) may exist simply because of the benefits they bring to people in positions of power and not because of the long-term conservation payoff. There are many other examples of powerful persons' reserving resources for their own use. In some Indian villages, Brahmin domination of village forest management councils allow them to capture most of the benefits of communal lands (Agrawal I994). Similarly, the kings of England set aside hunting forests that still serve as wildlife refugia. Stratification affords some individuals the power to police resources for their own benefit and perhaps to conserve them (again for their benefit). However, insofar as con- servation is achieved through direct coercion, chiefdoms are not an appropriate model for policy makers, at least enlightened ones.

In systems intermediate between bands of foragers and chiefdoms, such as pastoral and fishing communities, common property management practices are often observed. They owe their existence not to the policing actions of persons with hereditary rights and powers but either (following our model) to mutual interests in conservation among homogeneous individuals or to mild heterogeneity combined with weaker, nonhereditary powers of coercion. Unlike most foragers, pastoral and some fishing communities have had, at least in the past, considerable control over their resources, and unlike most stratified societies they rarely present sufficient inequalities in material wealth to permit total monopoly and/or exclusion of resources. Furthermore, these societies have sufficiently developed general institutional structures that can be used for these purposes. Under such conditions, we might expect conservation practices to arise as a stable equilibrium. There is, however, a rider to this: even in relatively unstratified systems, asymmetric interests and coercion may well be entailed in the generation of conservation outcomes, as the model reveals.

Communal resource management is frequently viewed not only as a panacea for environmental abuse but also as a socially just solution to environmental protection. There is considerable interest among conservationists and nongovernmental organizations in reconverting land (and marine areas) currently under open access or state ownership to a properly managed commons (and giving legal rights to what are now de facto commons), precisely because it is believed that such systems are more equitable. Prominent examples are the village-based wildlife management schemes in eastern and southern Africa, such as the Communal Areas Management Programme for Indigenous Resources (CAMPFIRE) in Zimbabwe, in which sport hunters buy the rights to hunt from local village committees (Metcalfe I 994) and the Administrative Management Design for Game Management Areas (ADMADE) in Zambia (Gibson and Marks I995). Such initiatives are based on the growing evidence that communal management systems have been historically and geographically prevalent and can work to protect resources for sustainable use (McCay and Acheson 1987, Berkes I989, Ostrom I990, McKean I992). Furthermore, environmental regulations that are based on traditional custom and sanctioned by community institutions are more likely to be respected than those imposed by external authorities, even where the regulations themselves are very similar (Stevens I997). However, these studies raise questions for a skeptical evolutionary ecologist about how collective action is achieved, as well as persistent worries about whether the system is merely run according to the interests of the primary rule makers, whose own interests coincide with environmental protection.

We have seen that in pastoralists, simply as a result of wealth differences, there may be considerable varia- 
bility among individuals over whether conservation is indeed the favored strategy. In our view communal resource management systems need closer scrutiny to see not only whether they afford biodiversity protection (or at least sustainable use) but how and why they work and potentially in whose best interest (see also IIED I994). The first question calls for social science research in conjunction with ecological research. The latter questions entail determining who the greatest beneficiaries of the conservation practices are, how these beneficiaries finance the regulations, and what these regulations cost others. The implication of our study concerning the impact of power differentials on conservation outcomes does not, of course, mean that we sanction the old-fashioned view that the poor stand in the way of conservation. In fact, our motivation is exactly the opposite. Similarly, Davis and Bailey (I996) argue with respect to traditional use-right fisheries of the North Atlantic seaboard that in fact "tradition" may be inequality of access. However, it is worth noting, as does E. Schlager (personal communication), that an asymmetrical distribution of power may simply be consolidated by state management of resources, since elites typically have better access to government agents charged with developing management plans.

The Barabaig are continually losing access to the Basotu wet-season pastures because of agricultural incursions that began in the I96os and accelerated in the I980s. Herders are now forced to use the Barabaig Plains at times of the year when these reserves should be resting and to maintain permanent homesteads in zones in which habitation was traditionally prohibited. Accordingly, elders can no longer enforce traditional sanctions. We suspect that under these unfortunate and all too common (Fratkin I997) circumstances a game-theoretical analysis of herding practices based on individually perceived costs and benefits becomes increasingly valuable, precisely because the traditional community norms have been undermined (see also Grabowski i 988). The current land use crisis in Hanang is rooted ultimately in economic conflict stimulated by institutional change at the national and regional levels.

\section{Comments}

FIKRET BERKES

National Resources Institute, University of Manitoba, Winnipeg, Canada MB R3T2N2 (berkes@

cc.umanitoba.ca). $28 \mathrm{v} 99$

Ruttan and Borgerhoff Mulder start with the arresting question "Are East African pastoralists truly conservationists?" and go on to analyze a much more fundamental question: If conservation strategies can be demonstrated for a group of people, what mechanisms serve to maintain such strategies despite the costs of restraint? Their analysis, using a game-theoretic approach, is well reasoned, expertly combining analytic thinking and ethnographic material. The model is based on decision making by individual herders, but it also takes into account power relationships-an innovation. Self-interest ultimately leads to a web of interdependencies and to a number of possible outcomes with regard to conservationist behavior.

In interpreting their results, the authors judiciously compare the approach of the literature on common-property institutions (e.g, McCay and Acheson 1987, Ostrom I990, Hanna, Folke, and Maler I996) with that of evolutionary ecology (e.g., Smith I983, Alvard I993, Winterhalder and Lu I997). Although their own approach is of the evolutionary ecological school ("We retain a paradigm based on individual self-interest" $\mid$, they reject two of the assumptions commonly used in evolutionary ecology: (a) that short-term foraging efficiency and long-term conservation are necessarily mutually exclusive and $(b)$ that overt conservation behavior must be clearly distinguished from the incidental effects of conservation. They could have gone farther in their critique of cost/benefit reductionism, an approach that takes little account of history, culture, and adaptations. I expand on this point not as a criticism of their work but as an extension of it.

There are good reasons, both cultural and ecological, to believe that common-property institutions and indigenous resource management systems cannot be explained solely in terms of cost/benefit accounting (Berkes and Folke I998, Berkes I999). Indigenous resource management systems are not mere traditions but adaptive responses that have evolved over time. These adaptations may involve the evolution of similar systems in diverse areas and cultures, as in the case of the shifting agriculture found in virtually all tropical forest areas of the world, or they may involve the elaboration of one basic model of management into a diversity of variations such as one finds in the reef and lagoon tenure systems of Oceania (Johannes I978). They may involve the transformation of the landscape from one production system to another, as in the evolution of irrigated rice systems in Southeast Asia (Geertz 1963). They may involve the combination of traditional approaches and contemporary commercial pressures into a new synthesis, as in the coffee agroforestry systems found in a diversity of cultures and geographic areas in New Guinea, Kenya, Nigeria (Warren and Pinkston I998), and Mexico (Beaucage and Taller I997).

An examination of the literature indicates that two features of these adaptations stand out (Berkes I 999). The first is the extraordinary similarity of basic designs shared by different cultures in comparable ecosystems worldwide, coupled with a remarkable diversity in practice even in adjacent areas. The second concerns the historical progress of these adaptations: they tend to proceed not in smooth and even steps but rather in fits and starts (Conelly I992). Geertz's study is a classic. Over some 400 years, irrigated rice culture developed from less intensive to more intensive modes of agriculture; productivity increased through the building of dikes, terraces, 
and canals, and this technology was developed in a twoway feedback relationship with appropriate institutions for collective action. The tools of the cost/benefit school of evolutionary ecology are too limited to deal with such transformations.

The question of whether a group of people is "truly conservationist" requires attention to a complex of historical and cultural factors-what Fienup-Riordan (I 990) calls the broader question of the relation of ideology to adaptations. From a number of well-documented examples (Berkes I 999), it appears that social learning and cultural evolution based on ecological knowledge, often following a resource crisis, are the major ingredients of developing conservation-oriented practices. Such a view of the evolution of conservation makes a distinction between invaders and natives. When humans invade a new and unfamiliar ecosystem, their impact on the environment may be substantial initially, but this initial relationship may change as they develop a knowledge base, learn from their mistakes, and come to terms with the limits of their new environment. A similar process applies to groups undergoing a social or technological transformation, resulting in the coevolution of groups with their environment, as with Geertz's rice farmers (for complementary evidence, see Conelly I992). Such transformations are not likely to happen over short periods, and feedback learning often requires making mistakes. A knowledge base takes a long time to develop and practices based on such knowledge even longer. Practices are grounded in institutions, and self-interest is brought into check by social norms and institutions such as those sketched by Ruttan and Borgerhoff Mulder for East African pastoralists.

JOHAN COLDING AND CARL FOLKE Centre for Research on Natural Resources and the Environment and Department of Systems Ecology, Stockholm University, SE-I06 9I Stockholm, Sweden (calle@system.ecology.su.se).28 v 99

In this impressive article Ruttan and Borgerhoff Mulder ask the important question where applied anthropologists and development workers should look for useful models for management of the commons. They skillfully demonstrate that conservation among Barabaig herdsmen may be motivated by purely selfish economic reasons and that economic efficiency may lead to conservation behavior. This finding contrasts with the assumption often made by evolutionary ecologists (e.g., Alvard 1993) that conservation and foraging efficiency are mutually exclusive. Through their game-theoretic approach Ruttan and Borgerhoff Mulder claim that "fortuitous" can be distinguished from "epiphenomenal" conservation. Thus, one value of applying a game-theoretic approach is to sort out cases of "fortuitous" conservation, which they propose to be more likely than "epiphenomenal" conservation to withstand outside forces for social-economic change.

Ruttan and Borgerhoff Mulder suggest that useful mod- els for commons management are likely to be found among common-property systems and call for closer scrutiny of these systems with regard to their capacity for conservation. Such an investigation was undertaken in a case-study volume (Berkes and Folke I998) with the emphasis on building resilience in combined social-ecological systems. We share with Ruttan and Borgerhoff Mulder an interest in looking at how and why commonproperty systems work, but rather than asking how and why particular institutional structures evolve rather than others we prefer to investigate how existing social mechanisms and management practices of commonproperty systems relate to resource and ecosystem dynamics over space and time, how they respond to environmental feedback. A major reason for this focus is the recognition that conventional resource management and conservation as practiced by governmental agencies and models of resource exploitation often lack the capacity for responding to environmental change (Holling and Meffe 1996). We are interested in adaptive institutional responses to ecosystem dynamics for conservation. For this purpose we combine insights in ecology from the use of systems approaches and adaptive management, with their emphasis on complex systems, linkages, and feedback controls (e.g., Gunderson, Holling, and Light I995), with those derived from studies of common-property systems that have demonstrated success in long-term resource and environmental management (e.g., Ostrom I990). The analyses have brought forward a diverse set of management practices and social mechanisms for conservation (or at least sustainable use) in complex dynamic ecosystems in both temperate and tropical regions and traditional and contemporary society.

A major finding of our work is the critical role of the ecological knowledge of the resource users themselves in such systems, whether traditional or contemporary. In short, ecological knowledge generated through experience facilitates the monitoring and interpretation of resource and ecosystems dynamics. It is an important component of institutional memory of how to respond to environmental crisis, disturbance, and other change. Hence, while individual self-interest may result in the evolution of many local-level institutions, successful management and conservation rest on the capacity to understand and adapt to environmental feedback over time as well as space. We have proposed that local-level institutions that build resilience for conservation of resources and ecosystem services of local ecosystems have a close fit to the dynamics of these systems (Folke et al. I 998). This may be part of the reason that some commonproperty systems survive and others do not. Furthermore, we believe that even cases of "epiphenomenal" conservation can be instructive for scholars devoted to conservation. We have elsewhere argued that unintended conservation mechanisms play an active role in preserving endangered species and that such institutional mechanisms even preserve important habitats (Colding and Folke I997, I999). What is promising is that similar institutional mechanisms have been proven useful in the 
redevelopment and design of active community-based conservation (Johannes I998). Since "epiphenomenal" conservation may have a close cultural fit that draws on culturally accepted norms and values, its redesign toward intended conservation may involve low transition costs of benefit in conservation.

ELLIOT FRATKIN

Department of Anthropology, Smith College, Northampton, Mass. oI063,U.S.A.lefratkin@ sophia.smith.edu). 9 vi 99

It is exciting to see the methods and theoretical perspective of evolutionary ecology, previously used for foraging populations, applied to pastoralist peoples. Many ethnographers of pastoralists, as well as members of these societies themselves, often talk about an inherent conservationism and "living in harmony with the environment." But actual decisions about where and when to graze livestock are usually driven by immediate needs without much concern for their effect on resource availability in the future. I am inclined to agree with Ruttan and Borgerhoff Mulder that "foraging decisions are made on the basis of efficiency maximization, and hence any conservation is fortuitous or even epiphenomenal." Ariaal pastoralists in northern Kenya divide their herds into milking and nonmilking stock, the former staying with the domestic settlements while the latter are herded independently in areas that offer the best grazing, water, and security-camels in salt-rich lowlands, cattle in highlands for water and grasses, and small stock in areas of sufficient browse and water. But I know of no case in which herd owners forsake proximate or safe pastures with the view of conserving them for another time. The major cost in choosing herding locations is the amount of available labor, usually unmarried male warriors who herd and protect the animals. While herd owners often band together to provide a sufficiently large labor force for their collective herds, decision making about grazing areas is usually by the wealthier and more influential men, as Ruttan and Borgerhoff Mulder show for the Barabaig (Fratkin I998:78-83).

As the authors of this article note, political factors almost always enter the picture in herding decisions. For the Ariaal this usually includes the presence of traditional enemies such as Turkana or Boran pastoralists, which can limit access to grazing or require a large body of Ariaal warriors to protect the animals. In drought situations, competing pastoralists in northern Kenya are forced to face each other and take the consequences. In July 1 996, Turkana raided and were counterraided by allied Samburu, Ariaal, and Rendille herders when all four groups grazed their animals on the LBarta Plains near Baragoi, Samburu District. Both sides suffered several deaths and substantial livestock losses.

One does not need to agree with all the tenets of evolutionary ecology or game theory to appreciate the logic and empirical evidence presented in this paper. Ruttan and Borgerhoff Mulder anticipate the usual criticisms of the evolutionary ecological framework-that it ignores political or socioeconomic factors while concentrating on cost/benefit analysis in decision making. They spend a fair amount of time analyzing wealth and power differentials identified through ethnographic observation of Barabaig pastoralism. The wealthier and influential members of the Barabaig community influence the grazing decisions of others by encouraging poorer herders to graze with them when it is advantageous for them to have large numbers of animals close together and discouraging them when it is disadvantageous. Among Ariaal, where wealth is based on large herds of camels or cattle rather than large flocks of small stock (goats and sheep), camel and cattle owners can distance themselves from competing small-stock herders either by grazing cattle in highlands too wet for small stock or, with camels, grazing at great distances from permanent water sources. Herd diversity is not a feature discussed by Ruttan and Borgerhoff Mulder, but that may owe more to Barabaig's specialized raising of cattle (like the Maasai), made possible by the richer grazing resources of northern Tanzania, than to the multiple-species pastoralism practiced by the Ariaal, Turkana, and other groups in the semidesert environment of northern Kenya.

Ruttan and Borgerhoff Mulder make an important contribution to pastoral studies by adding an evolutionary ecological perspective to a field that has successfully employed an ecosystems approach (Fratkin, Galvin, and Roth I994, Little and Leslie I998). In turn, pastoralist experiences may well contribute to the development of evolutionary ecological theory.

JOHN G. GALATY

Department of Anthropology, McGill University, 855 Sherbrooke St. W., Montreal, Quebec, Canada $\mathrm{H}_{3} \mathrm{~A}$ 2T7 (john.galaty@span.ch). Io vi 99

It is too often assumed that it is the poor who use collective strategies to defend communal resources from appropriation or monopolization by the rich, conservation being in this regard tied to social equity. Drawing on the power of formal models to generate new, theoretically based knowledge, Ruttan and Borgerhoff Mulder's article on East African herder conservationist behavior has the substantive virtue of demonstrating how conservationist strategies may be associated more with richer herders, who have much to gain by keeping (dry-season pasture) resources "on the shelf," than with poorer herders, who have less to gain. The major drawback of formal models is that they may be misinterpreted as representing the complex world of events rather than simplified accounts that, "everything else being equal," help us to think. Accordingly, the article has demonstrated not that rich herders are in fact more conservationist (of dry-season pastures) than poor ones but only that there is a reason that, under certain circumstances, they might be. Moving to wet-season pastures may be in richer herders' interests, since their larger herds will disproportionately benefit from grazing retained in dry- 
season pastures, while the poorer may feel that gaining early access to dry-season pastures will benefit them more. Moreover, enforcing conservation of the dry-season pasture may require the political power and influence held by the wealthier. Thus, the authors seem to argue implicitly, the conservationist option may not only be compatible with but depend on wealth differentials-an important proposition. I would like to make four observations that bear on how their model relates to the tangible world of pastoralists.

I. In emphasizing the costs of moving to wet-season pastures (while conserving dry-season pastures), the authors may have neglected the virtues that make early and continuing use of the wet-season pastures that arise from rainfall positively desirable: wet-season grasses are young, succulent, easier for ruminants to digest, and full of nutrition. Also, animals in wet-season pastures drink water from standing pools that is warmer, saltier, more palatable, and healthier than the water from wells or springs common in dry-season pastures. The assumption that herders in fact desire to occupy dry-season grazing areas stems primarily from 2oth-century experience in East Africa, where trading centers were established near permanent water and cultivators under pressure have tended to encroach on areas of perennial vegetation, including precious swamp lands. In general, wet-season pasture is the most desirable, dry-season pasture what herders fall back on when the wet-season pasture is gone or when scarcity of water makes it unavailable.

2. More common than the predicament of whether to move to wet-season pastures at all is that of how early in the dry season to move back from wet-season pastures to dry-season pastures. This judgement involves weighing numerous factors: whether to remain using wet-season pastures when pools have dried up at the cost of making long moves to access more permanent water, whether to take the chance of seeking possible pastures away from other herders or choose the more sure but undoubtedly less rewarding option of congregating near others, whether to minimize distance from water while forgoing the best pasture or vice versa, etc. It is for such situations of pressure and potential conflict, when multiple options and diverse outcomes are available, that rules for collective action are most often devised to guide herders in making their judgements; such rules may be followed or broken, enforced or renegotiated, and applied with or without sanctions. The added weight of the richer herder in not only following but reinforcing rules for collective action is crucial at this juncture, when individual and group interests may most diverge.

3. Ruttan and Borgerhoff Mulder observe that networks of rights and obligations have "distracted" ethnographers from individual self-interest, but surely herders have always served to instruct us that functional social groups, collective norms and sanctions, and networks do not contradict the energetic pursuit of selfinterest but offer some of the means for it. Herders daily decide where it is in the interest of herds and of the humans that herds support to graze, how to juggle interests of milk-drinking calves and people, whether to share or to withhold information, whether to pool labor or keep herds autonomous, etc. Self-interest is not pursued by Homo economicus alone, and surely a complex social science can recognize that self-interest and social embeddedness are reciprocals rather than viewing the latter as a precipitate of the former.

4. It is as a necessary corrective to undue idealism about the ecological harmony of herders and foragers with nature, with its assumption that conservationism tends to be altruistic rather than self-interested, that the authors' argument is fashioned. However, in focusing on one aspect of herder strategies-the pursuit of conservationist strategies-they may discount other, more complex dimensions of pastoral behavior that are guided by accumulated knowledge, collective strategies, and cultural procedures honed by experience. The Ostrom (I990) fables of common resource management may be too neat to typify the highly flexible, opportunistic, and responsive systems by which common herding resources are accessed, including the continuous and often unpredictable responses of herders to one another, producing "coordination" between them that is an outcome of both intention and stochastic process. Recent work in the "new" rangeland ecology suggests that the remarkable long-term success of pastoral systems is predicated less on the establishment of an equilibrium with nature through the imposition of systemic behavioral and cultural constraints that the conservationist model seems to imply than on the interaction of a highly dynamic process of animal production and husbandry with a highly resilient dryland ecosystem that is capable of absorbing periodic, short-term grazing pressure when rainfall is low because of its remarkable powers of recuperation when rains return (Scoones I995).

To point out the underlying politics of the argument, describing their conservationist capacities seems to provide a scaffold of managerial virtue to support pastoralist claims to land, but to put undue emphasis on pastoralist conservationism may in fact "set them up" when the gap between cultural ethics and reality is inevitably manifested, thus inadvertently weakening their claims to land today. After all, pastoralists have endured a long history of disparagement because of their practice of economically dynamic herd buildup and highly mobile and extensive forms of range use. "Mainstream" range management has long considered these practices detrimental to long-term range quality, a view contradicted time after time when the return of rainfall has brought virtually full regeneration of pastures (Sandford I983). Conservationism among pastoralists is too fickle a measure on which to base their claims to land, which are best grounded in rights of occupancy, a history of continuous use, and the cultural centrality of pasture land holding. The "harmony" that pastoralists establish with nature is more of a loose bargain between two highly volatile competitors than a reciprocal vow between docile partners, and the conservation of dry-season pasture whenever and as long as it is possible but no longer is part of that bargain. A key contribution of this article is demonstrating that pastoral conservation practices conjoin 
individual and collective interests as herders coordinate their behavior to make the most of the rich but meager resources they are allotted by history and chance.

KATHERINE HOMEWOOD Department of Anthropology, University College London, Gower St., London WCIH oDD, U.K. (k.homewood@ucl.ac.uk). 2 I vi 99

Ruttan and Borgerhoff Mulder's model has considerable heuristic value. My commentary explores three main points. First, are the pastoralist institutions that control grazing access likely to be primary determinants of rangeland persistence? Second, are the costs built into the model really those most appropriate for analysing pastoralist decision making about grazing management? Third, is it a useful first approximation to model pastoral land-use decisions as determined primarily by tradeoffs between livestock production and labour costs for different wealth categories?

Most arid and semi-arid grazing ecosystems are highly variable, shift chaotically between multiple alternative states, and are perhaps best described by disequilibrium or non-equilibrium dynamics (Behnke and Scoones I 993; Ellis and Swift I988; Sullivan I998, n.d.). In these systems, livestock grazing pressure is increasingly thought to be a minor, negligible determinant of long-term vegetation state and associated biodiversity compared with other biophysical factors, particularly rainfall. Livestock grazing pressure may have no significant carryover for rangeland productivity from one year to the next (Sandford I982). Where this is the case, long-term environmental trends are largely uncoupled from pastoralist grazing pressure, which renders less valid this model's whole approach to the question of whether pastoralists are conservationists. It is tempting to see pastoralist grazing management in conservation terms. However, pastoralist management is geared to seasonal shortages, with arguably little or no bearing on long-term vegetation state (e.g., Mkomazi [Brockington I998, Brockington and Homewood I998, Homewood, Kiwasila, and Brockington I997, Rogers et al. n.d.]). Seasonal shortages are occasionally severe and drastically exacerbated by any uncontrolled influx of outsiders but have had no measurable implication for long-term trends (Homewood and Brockington n.d.). Using a Western idiom, the problem faced by most pastoralists in their management of grazing is not the central conservation issue of how to live off the interest without eating into the capital but, rather, how to get through the cash-flow crisis until the paycheque arrives at the end of the month. The model deals with the first, but pastoralist grazing management focuses on the second. Does this model really address the question it purports to answer?

The model hinges on the costs of wet-season pasture use. However, in most of the systems with which I am familiar, wet-season pasture use has overwhelming benefits, while the alternative of staying on in dry-season refuges has serious disadvantages. The paper hints at this possibility but glosses over its implications, Transhumance between dry- and wet-season pastures is epidemiologically safer for livestock (Sandford I983, Waller and Homewood I997). Wet-season pastures are widely seen as nutritionally superior to dry-season grazing areas (Bell I982). In many pastoralist areas the spread of privately owned, fenced land has made it increasingly difficult to move between wet- and dry-season pastures (e.g., Meru/Arusha [Spear I997]). Many former wet-season pastures have been gazetted as protected areas where grazing livestock is prohibited and severely punished (e.g., Mkomazi [Brockington I 998, Homewood, Kiwasila, and Brockington 1997] and the Serengeti short-grass plains, still used by Maasai [Homewood and Rodgers I99 I]). However, even factoring in the physical difficulty of movement and penalties for crop damage or illegal use, the benefits of transhumance to wet-season pastures are overwhelming. Thus it may be misleading to see pastoralist behaviour in terms of game-theory cooperate/ defect dichotomies. Decisions may be more to do with the degree to which they can move given the problems of tenure and access in modern pastoralist systems such as those of Botswana (Hitchcock I990) or Maasailand in Kenya. Wet-season pasture is used wherever possible, even if that use is illegal and carries massive penalties. If the cost term is usually a positive benefit, this must undermine the model's ability to dissect the important components of decision making.

Finally, throughout African rangelands, rapid privatisation has meant that wealthy pastoralists continue to access common resources and then retreat to privately owned resources, excluding poorer pastoralists, once the commons are exhausted (e.g., Botswana [Hitchcock I990], Somalia [Behnke I983]). The model conceives of Barabaig and other pastoralism as closed grazing systems, whereas in fact they are shaped and driven by outside forces far too important to omit. Real-life systems do not meet two of the authors' four conditions for conservation, namely, a mechanism to exclude outsiders from resources and an absence of alternative opportunities for investment with higher rates of return. Maasai around the Mara may retain a culture strongly shaped by pastoralism but operate in a world where decisions over rangeland are primarily influenced by land markets, commercial cereal farming, and wildlife viewing enterprises (Norton-Griffiths I998). Political and economic interactions between resident Maasai and outside entrepreneurs, officials, and elites are converting land around the Mara to a massive wheat belt (Dietz I996, Muraguri I999). Similar influences in a different macroeconomic and political context drive land-use change in Barabaig country. Where Ruttan and Borgerhoff Mulder consider the possibility that rich herders discount future payoffs at a lower rate of return than do the poor and see that "the people with the most power are also those most interested in conservation and this may be an important reason that pastoralists often seem to be successful in protecting their commons from degradation," there is a strong incentive for the rich to convert to alternative investment, and financial and political elite outsiders 
cannot realistically be excluded. Pastoralist management retains conservation-compatible rangeland and makes the most of livestock production opportunities within those variable and unpredictable rangeland ecosystems without otherwise much affecting conservation outcomes, but alternative investment opportunities rapidly change this. The authors feel that a game-theoretical analysis of grazing management based on individual perceived costs and benefits becomes increasingly valuable under the increased pressure of conversion of rangeland to cultivation and the disintegration of customary regulation and enforcement of access rules. It seems more likely that the economics of extinction (Clarke 1973, May 1994, Caughley I993) become increasingly relevant as asymmetries of power, wealth, and payoffs combine with a changing scale of returns to encourage alternative investment and widespread loss of rangeland habitat.

PETER D. LITTLE

Department of Anthropology, University of Kentucky, Lexington, Ky.40506-0024, U.S.A. (pdlittı@

pop.uky.edul. 3 vi 99

Ruttan and Borgerhoff Mulder address an age-old question about whether East African herders are ecological conservationists or villainous destroyers of the environment. They avoid recent debates regarding herders' role in wildlife conservation and biodiversity (see Little I996, Western I994) and, instead, focus on pasture and land conservation and propose a model of pastoral decision making to explain tendencies to conserve or degrade range resources. This approach is based on game theory, and they simulate a range of different scenarios ("games") based on decisions about seasonal livestock movements. For many social and cultural anthropologists, their assumptions about herder self-interest and the absence of exogenous political economic forces will seem problematic, overly simplistic, and blatantly unrealistic. The analogies to evolutionary ecology will also create some discomfort (as they do for me), but I recommend that readers move beyond hasty judgments and look at the essence of what the authors are proposing. They offer a novel way to understand why pastoral strategies of economic gain are not inherently inconsistent with conservation goals. It revisits the "tragedy of the commons" debate, but unlike previous critiques it allows herders to be individual agents rather than Rousseauian communalists or "natural" conservationists. Let me elaborate on why their model is worth considering.

The framework presented by Ruttan and Borgerhoff Mulder addresses perhaps the most important set of decisions a herder makes: when to move and what pasture and water resources to move to each year. In the ethnographic example that they refer to, the Barabaig of Tanzania, these pastures and water points are regularly moved to each year with only minimal deviations. Unlike the proponents of other formal representations, they recognize that pastoral communities are divided along wealth lines and that the benefits and costs of different decisions will vary according to wealth; the model invokes a twofold classification of herders, rich and poor. The skeptics will challenge the simplicity here: where are age, clan, and gender as principles of social differentiation, and what about other types of decisions (livestock lending, marketing, and consumption) which herders must regularly make? No doubt the more variables that are added, the more unwieldy the model becomes and, consequently, the less useful. I agree that the major basis of herder heterogeneity is wealth and that the most important annual decisions center on the timing and location of herd movements.

Another positive aspect of this article is the authors' relatively good understanding of Barabaig ethnography and their recognition that this group represents a unique case of transhumant pastoralism and therefore the model will need considerably more empirical testing elsewhere in the region. In contrast to other formal models of decision making, where at best ethnographic validity and testing are not high priorities, the authors' approach is refreshing. Ruttan and Borgerhoff Mulder anticipate challenges from institutionalists and structuralists by demonstrating that individual self-interest-which is culturally determined-does not have to conflict with collective norms and institutional interests. Conformance to social norms about grazing rights and uses does not require individual herders to forgo their own interests and goals; these can be complementary or conflictive. Pursuing individual interest does not necessarily result in destructive "free riding" or open access, problems that underlie neoclassical attacks on the effectiveness of common-property systems like those of East Africa.

There a few areas, nonetheless, where their model needs some reworking. The first is that it unnecessarily privileges individual self-interest. Why use the individual as the key unit of analysis? (In fact, the individual and the "household" [a collection of individuals] are often used interchangeably.) Since we know that larger units such as lineages and extended-kinship-based compounds have vested rights and interests in herds, why not use a larger social unit, which may be ethnographically more accurate than the individual? Secondly, game theory assumes that "players" can calculate or rank the outcomes of different decisions that are made. This may be appropriate in a relatively stable transhumant system, where herd movements are fairly predictable and outcomes can be ranked and a risk element (probability) attached to them. But what about in nomadic, unstable systems, where movements are more random and uncertainty (i.e., the inability to rank the probability of outcomes) the norm? How appropriate are game-theorybased models in these kinds of systems?

To conclude, as in all models a certain degree of simplicity has to be maintained, and despite the shortcomings mentioned above Ruttan and Borgerhoff Mulder's model is an important departure from strict descriptive accounts in the direction of comparative analyses of herder decision making and conservation. 
ELINOR OSTROM

Workshop in Political Theory and Policy Analysis, Indiana University, s 3 North Park, Bloomington, Ind. 47408-3895, U.S.A. (zielinski@indiana.edu). $24 \mathrm{~V} 99$

Ruttan and Borgerhoff Mulder present an important analysis of how pastoral people, who face many temptations to overuse the natural capital on which their livelihood depends, deal with the resource dilemmas they face. Current views of indigenous resource users, including pastoralists, forest users, and fishers, tend to represent extreme positions. Some consider indigenous users as noble savages who are natural conservationists. Others regard them as narrow hedonists whose overuse leads to repeated tragedies of the commons. Ruttan and Borgerhoff Mulder bring a refreshing evolutionary perspective that eschews both extremes.

By analyzing a game between a set of herders owning a large number of cattle (the rich herders) and a second set of herders owning only a few cattle (the poor herders), they show specific conditions under which a conservation outcome will occur as a result of the decisions the two kinds of herders make. Each set of herders faces the decision to move its cattle at a cost to a wet-season pasture or to stay in the dry-season pasture, which generates externalities for the other set (as well as for itself over the long run). The results of their analysis show the conditions that are consistent with utility-maximizing pastoralists' adopting the strategies leading to a conservation of the dry-season pasture because of the benefits they achieve thereby. Further, their work illustrates that heterogeneity is not always a hindrance to the achievement of conservation outcomes.

Their results are consistent with research on the Nuer (Duany 1987, 1992) as well as research related to other common-pool resources, such as forest resources (Gibson, Ostrom, and McKean 2000), and even global resources (Ostrom et al. I999). Further, their analysis of rules that establish pastures to be used in different seasons of the year but also punishments for noncompliance illustrates the universality of rules, monitoring, and sanctioning when indigenous peoples are able to find ways of using resources in a sustainable manner. For I 5 years I have been searching for cases in which an indigenous people with a high demand for the use of a resource had conserved that resource without the kind of rules discussed in this paper and have not yet found a single such case.

Thus, I think Ruttan and Borgerhoff Mulder have identified some of the crucial elements of how indigenous peoples do actually conserve the resources on which they depend. Their creative use of game theory, combined with an in-depth knowledge of how a pastoral people deals with a common problem faced by all such peoples, adds to our knowledge of how conservation is achieved.
HERBERT H. T. PRINS

Tropical Nature Conservation and Vertebrate Ecology Group, Department of Environmental Sciences, Wageningen Agricultural University, Bornsesteeg 69, 6708 PD Wageningen, The Netherlands (Herbert.Prins@ staf.ton.wau.nl). $26 \mathrm{v} 99$

Ruttan and Borgerhoff Mulder consider whether indigenous people could live in "harmony with nature" without driving the exploited natural resources into extinction and whether "conservation" is practised by traditionally living people. These two ideas are often fused in the minds of scientists, and when indigenous people do not wipe out the resources they exploit they are believed to be living in harmony with nature and practising conservation. This can lead to heated debates, for example, on whether native North Americans caused the extinction of the mammoth and other large mammalian species (see Martin and Klein I984).

Before entering into such an argument, it should be ascertained whether people who depend on local resources are limited by those resources. Only if they are is it relevant to ask whether they are exercising restraint in their resource exploitation. The debate immediately becomes a non-issue when people are not limited by their resources but are limited otherwise. If numbers are much below carrying capacity, large tracts of their range will be left unutilized or underutilized simply because there is no need to use the resources. People then are not living "in harmony with nature" but controlled by nature, often in an awesome way through crippling and debilitating diseases, and the concept of "conservation" does not apply: the indigenous population does not need to use all its resources, and, if there is no trade with other groups, there will be no drive to increase their exploitation. Suppose, however, that local people are limited by the resource. In the case of the Barabaig, it is likely that with modern medicine the size of the local human population is determined by the produce of their cattle, on which they depend for both sustenance and trade (see Klima I970, Lane I996). It is therefore essential to look at their livestock ecology and production.

Ruttan and Borgerhoff Mulder point out that the Barabaig preserve nearby grass resources during the dry season, which, they assert, is unusual for African pastoralists. They then state that "we do not even include the fact that the forage on the Basotu Plains [where the wetseason range is] is seen to be of higher nutritional value than that on the Barabaig Plains." They go on to model the question whether a herder should "'defect' and remain in the dry-season reserves year-round"-that is, whether a herder should forgo good grazing and stay yearround in an area that is nutritionally less good for his livestock. This is a strange question to ask, because we know that in the East African savanna systems it is not the quantity of food which limits herd production but its quality (Pratchet et al. I977, Ketelaars 1986, Prins I996). Forage quality includes digestibility, energy content, nutrient content, and even the amount of anti-feedants. Irrespective of place, grass quality is higher in the 
wet season (when growth is high) than in the dry season, and grazing can maintain the sward in a high-quality state for quite some time. Ruttan and Borgerhoff Mulder construct a payoff matrix based on a currency "measured in arbitrary units of livestock survival and productivity, which are an unspecified function of grass intake," but livestock survival and productivity are, as I have said, much more a function of forage quality than of forage quantity. Their quantitative model cannot easily take into account quality because of a strong scale effect: if in the absence of other grazers a herder forgoes grazing, then his action will cause the grass to be underutilised, which causes a quality decline, and if the other herders are too far away, then they cannot capitalise on the setaside grass and forestall this decline. In that case, no simple payoff matrix can be constructed. Within a small area (say, a patch of a few hectares) quantity and quality can perhaps be treated in the same way (see De Boer and Prins 1989, Prins I996), but the current Barabaig problem is on a much larger geographical scale. Therefore the way Ruttan and Borgerhoff Mulder analyse the pastoralists' choices is unrealistic: forage quality, which is the essential parameter from the point of view of both livestock and herder, should be the focus of attention.

In trying to understand the migratory pattern of livestock and wild herbivores in the nearby Masai ecosystem, where animals move between the Simanjiro Plains (where, as on the Basotu Plains, there is no surface water during the dry season) and the area along Tarangire River (to which game moves in the dry season and which is comparable to the Barabaig Plains), Margje Voeten and I (n.d.) chose a different approach. We used linear programming to determine whether cattle or wild game production could be optimalized within the nutritional constraints in these different areas. We successfully modelled where the animals should be at different times of the year and concluded that neither pastoralists nor migratory wild animals move to areas that are clearly inferior from a nutritional point of view. I therefore postulate that Barabaig behave optimally by staying away from certain areas (the Barabaig Plains) during the dry season. Although set-aside conservation is widespread in pastoral societies with regard to both forage and wild animals (see, e.g., Huntingford I953a, $b$; Stone I972; Waller I976), I am convinced that what Ruttan and Borgerhoff Mulder describe for the Barabaig has nothing to do with "conservation" (that is, setting an area aside for future use), let alone with biodiversity conservation, but is "only" a strategy aimed at maximizing the production of milk, calves, and money within the constraints of water availability and forage quality. Conservation for the sake of preserving biodiversity is, I think, unknown among pastoralists. Their numerical response and that of their livestock to the introduction of modern medicine and improved exchange of goods has led to the reduction of wildlife (Prins I992), a process which still continues. Most of this wildlife depends on the same resource as livestock does (Voeten and Prins n.d.).
ERIC A. SMITH

Department of Anthropology, University of

Washington, Box 353 I00, Seattle, Wash. 98195-3100,

U.S.A. (easmith@u.washington.edu). I vi 99

The implications of this article extend far beyond the particulars of East Africa or pastoralist systems in general. Coupled with other recent work on the evolutionary ecology of conservation (see review in Alvard 1998), it provides the basis for a rigorous and powerful theory of conservation and its failures. By paying attention to the social dynamics behind resource utilization outcomes, Ruttan and Borgerhoff Mulder both increase the anthropological interest of this work and provide a means of articulating it with the substantial literature on the politics of communal-property management (e.g., Ostrom I990, Feeny et al. I990, Ostrom et al. I 999). In particular, their analysis of the role of heterogeneous interests and coercion in stabilizing conservation in a nonstate political economy is a major and original contribution.

As they note, careful modeling using evolutionary game theory can be a very useful tool for explaining "when, where, and why we might expect people to adopt conservationist strategies" of resource management. Some readers (and probably some commentators) will respond to their analysis by asserting that the evolutionary component is superfluous because "it's just economics." No doubt we can frame virtually all their arguments in purely economic terms, as long as we are willing to take certain postulates (such as self-interest) as axiomatic or common sense. But pure economics for pure cultural logic, for that matter) can never explain why decision makers treat a given consequence (e.g., starvation of one's cattle) as a cost and another (e.g., healthy and well-fed offspring) as a benefit. Evolutionary theory provides a means of turning the primordial assumptions of economics and folk psychology into theorems explained by underlying processes; it also provides a powerful framework for generating expectations about behavioral design, as this article amply demonstrates.

Despite my very positive overall assessment, I do have some criticisms. First, it seems to me that in any society the rich are always more likely to conserve, as the costs to them (expressed as proportion of their total wealth or as marginal effects on their fitness) will be lower than for the poor. Therefore this finding is not surprising or unique to East African pastoralists. Less obvious is whether the wealthy are more likely to benefit from resource conservation. I find this part of the argument plausible but not very robust, as it hinges on the wealthy's getting a higher rate of return from a given amount of conservation. But this assumes that there is a linear utility (or fitness) function for cattle, meaning that each additional head of stock is worth an equal amount (in the herd owner's decision-making calculus). Yet isn't it likely that a poor person with few cows values each head more highly than does a wealthy herder with a larger margin between his present condition and destitution?

Second, I have some quibbles with the way the article characterizes the approach to conservation taken by ev- 
olutionary ecologists. Ruttan and Borgerhoff Mulder criticize the assumption that conservation is an alternative to economic maximization, which they ascribe to evolutionary ecologists, and urge us to move beyond it. While it is true that several researchers have posed efficiency maximization and conservation as competing alternatives in testing hypotheses about prey choice, these same researchers (and others) have also noted that conservation can enhance long-term efficiency if certain conditions (such as restricted access) are met (see Hames I 987 for further discussion). In addition, the ways in which efficient land use can result in "epiphenomenal" conservation have been repeatedly noted, beginning with Winterhalder (I98I) and Hunn (I982). The authors recognize as much at various points in the article, but, given the eagerness some have to paint evolutionary ecologists as enemies of the people (e.g., Alcorn I995), this may be overlooked.

Third, I am not convinced by the attempt to qualify or virtually explain away the findings of several researchers that contemporary foragers do not conserve game resources. For one, there are now some fairly strong archaeological data that document overhunting, in some cases to the point of extinction (e.g., Broughton I994, Anderson 1997). The argument that contemporary foragers "are nowadays relegated to habitats that are marginal" and are forced by hunger to overexploit resources is faulty, because $(a)$ populations will generally equilibrate to resource density, hence aggregate resource density does not equal per capita resource supply, $(b)$ many contemporary small-scale societies have undergone recent population declines due to introduced diseases, and (c) if resource scarcity is enough to eliminate conservation in these societies, then it could never be very effective in practice, since the whole point of conservation is to limit exploitation when demand exceeds supply.

Finally, a clarification about the role of intent in defining or identifying conservation: In my comment on Alvard (I995), from which Ruttan and Borgerhoff Mulder quote, I went on to note that if "intentionality is too narrow a requirement, we might expand it to 'intention or design,' where 'design' can refer to a nonintentional process such as natural selection" (Smith I995:8Io). Thus, my definition requires that true conservation not only reduce or prevent resource depletion but be designed to do so by the operation of some mechanism. The only naturalistic design mechanisms I know of are intentionality (and its subset rational choice) and natural selection (acting on genes or on culture). At the level of proximate mechanisms I judge intention to play a larger role in the design of human conservation strategies than natural selection. But the human ability to design anything and to engage in decision-making, as well as the motives and values that guide decision making, are ultimately products of cultural and genetic evolution, so of course I would grant natural selection primacy in that ultimate or long-run sense.

\section{Reply}

LORE M. RUTTAN AND MONIQUE BORGERHOFF MULDER

Davis, Calif., U.S.A. 8 vII 99

We are grateful to all the commentators for their thoughtful remarks and fresh ideas. As almost all of them appreciate, the primary goal of the article is to explore theoretically the mechanisms whereby conservation behavior might arise. As Galaty nicely puts it, we have "demonstrated not that rich herders are in fact more conservationist (of dry-season pastures) than poor ones but only that there is a reason that, under certain circumstances, they might be." The idea that benign conservation outcomes can result from individual economic maximizing strategies has been around for some time, and, as Smith and Ostrom point out, our contribution is to specify more precisely the conditions under which this might occur; this is important for both theoretical and practical reasons. We did not intend the article as a treatise on the overall environmental impact of pastoralism, and for this reason we regret a last-minute change in title to make it more catchy and to reflect our argument that fortuitous conservation is still "truly" conservation. We organize our discussion of the commentators' ideas into four sections: (I) the evolutionary ecological approach in relation to anthropology, (2) the interface of our work with common-property theory, (3) the appropriateness of the Barabaig example, and (4) the implications for conservation.

I. We greatly appreciate the open-mindedness of our anthropological colleagues. Most of them, some quite candidly, do not buy into an evolutionary approach predicated on the broader theory of evolution by natural selection. Nevertheless, they recognize the value of our analysis and offer their own insights, empirical support, and sensible amendments. A further problem is that models inevitably simplify reality to its bare bones. This is something with which ethnographers, reveling (quite rightly) in the detail of cultural diversity, are uncomfortable. By focusing on wealth and mobility we seem to have hit on dynamics that anthropologists studying pastoralism (Fratkin, Galaty, Little) believe merit such a formal treatment.

The position we took as regards evolutionary ecology is subtle and could possibly be misunderstood, as Smith cautions, so let us be more explicit. We strongly support an evolutionary ecological approach to the study of human behavior and appreciate (as we noted in the paper) that scholars like Hames and Alvard do accept that conservation (or stinting) can enhance long-term efficiency. Our goal was simply to determine more precisely the conditions in which this might be the case. To clarify (even though none of our commentators suspect otherwise), our aim was not to discredit previous evolutionary ecological studies in this area (we benefited enormously from the friendly fire of Michael Alvard, Hilly Kaplan, 
and Eric Smith in this respect) but rather to meddle with some of the assumptions of previous models; in particular, we strove to incorporate political realism, since social scientists rightly see the lack of this as a shortcoming of evolutionary models. By exploring the potential problems in heuristic contrasts of conservation with efficiency-maximizing strategies (problems that evolutionary ecologists themselves recognize), we hope to have added to rather than discredited evolutionary ecology's contribution to anthropology.

We are particularly grateful to Smith for pointing out why evolutionary ecology is not "just economics." In this context he raises the important issue of the utility (or fitness) value of livestock, noting that our model assumes that this relationship is linear, that is, that each additional head of stock is worth an equal amount in the herd owner's decision-making calculus. Although the relationship is in actuality not quite linear (returns diminish slightly), his point is valid. We acknowledged this problem and, indeed, cited some of the extensive evidence that richer herders look after their livestock less well than do poor herders (but see Sieff I999), a finding that is strongly suggestive of just such a diminishing utility function. At the same time, we are not convinced that the condition of the rangeland is of diminishing utility to wealthy herders, which is really our thesis. By this we mean that wealthy pastoralists may have longerterm interests in pastoralism because they are less likely to drop out of the pastoral mode of production altogether (e.g., Sieff I999); thus the benefits of conservation offset diminishing returns on milk production by additional cows. It is true, however, that our model does not fully address this issue. Although we incorporate the effect of large herds' leaving less grass for the dry season, we do not (as we pointed out in the paper) include any costs to running out of dry-season forage such as death of cattle or reduced productivity from moving to the tsetse-flyinfested woodland. Finally, Smith notes that a greater interest in conservation by the rich is not surprising given that the costs of moving cattle are a smaller proportion of their wealth. However, in another version of the model we calculate costs as a function of numbers of cattle (Borgerhoff Mulder and Ruttan 2000), and the overall patterns of results remains the same.

Germane to the previous argument about whether rich or poor herders have a greater interest in conservation (and still linked to the issue of utility functions) is Homewood's point that richer herders have special opportunities for diversifying their productivity. Examples abound in the literature of households with large herds moving into cultivation, marketing, ecotourism, and even long-distance haulage. Under such conditions there may well be conflict among richer herders over rangeland management, specifically between those with and without long-term vested interests in the pastoral economy. There are indeed intriguing instances of such tensions among the wealthy pastoralists with houses in the local towns of Hanang, Mbulu, and Mpanda Districts (personal observations by Borgerhoff Mulder, I987-89, I995-99). This could even lie behind some of the recent splintering in interests among different Masai NGOs. On top of all of this, families with small herds, who are constantly anticipating dropping out of pastoral production altogether (Sieff I999), may also view rangeland condition as an irrelevant common good. Clearly, as Smith gently hints, a closer look at how utility functions vary within (and between) populations could give the model as yet unrealized potential.

Finally, three minor points on evolutionary models: First, Berkes raises an interesting and thoroughly controversial issue, that the cost/benefit framework of evolutionary ecology is not well suited to dealing with the fits and starts of historical transformation. This taps into the old debate over gradual versus punctuated evolution, which we will not broach here. We would, however, like to bring interested readers' attention to a nice discussion of how an evolutionary approach can account for both the long periods of apparent stasis and the rapid change seen in human history and prehistory (Boyd and Richerson 1992). Second, we suspect that we talked past Smith with respect to our views on contemporary foragers. Smith is not convinced by our "attempt to qualify or virtually explain away" the findings that foragers do not conserve game resources. Indeed, we find the evidence he cites irrefutable! All we were suggesting was that conservation may have been more likely in the past if foragers had access to a wider variety of substitutable foodstuffs than do some marginalized groups today. Third, we apologize for mischaracterizing Smith's statements on intentionality by giving undue emphasis to intent rather than design by natural selection. We should have cited him for our fourth as well as our fifth definitional criterion.

2. The research of common-property theorists has blossomed over the past I 5 years. Though very catholic in their disciplinary affiliations and methodologies, these theorists view models predicated on strict cost/benefit payoffs to the individual as lying within the context of a broader family of rationality models (Ostrom I998), ranging from models predicated on raw self-interest to those in which individual interests are heavily constrained by trust, assurance, reputation, and norms. Against this background Berkes points out that "common-property institutions and indigenous resource management systems cannot be explained solely in terms of individual cost/benefit accounting." We are in complete agreement that norms and institutions constrain individual behavior. However, we argue that within these constraints individuals still have the choice of actually following the rules and norms, either course of action potentially being in their own best interest. This difference in viewpoint is, we suspect, largely a matter of emphasis rather than a substantive difference. The comments of Galaty and Little would seem to reinforce our position here. Galaty points out that on a day-to-day basis pastoralists face very real decisions over whether or not to comply with the rules, proposing that collective norms and sanctions "do not contradict the energetic pursuit of self-interest but offer some of the means for it." In a very similar vein Little suggests that "individual 
self-interest—which is culturally determined-does not have to conflict with collective norms and institutional interests," and Fratkin emphasizes the importance of economic constraints and objectives at the household level. We would probably all agree that self-interest and social embeddedness are often reciprocals but cannot deny the fact that many turf battles within the social sciences, and indeed between the social and the natural sciences, have been fought over this issue; that is why we gave it considerable attention. As Ostrom (I998) notes, one of the biggest challenges in the social sciences is to come up with a robust model for why humans are so cooperative in some cases and in others so shortsighted and nasty. One final point that we would wish to reiterate in this context is the fact that when commonproperty-management institutions become destabilized for whatever reason, with the concomitant breakdown in rules, trust, and community sanction, individual interest is particularly likely to become salient (Grabowski I988). We would therefore argue for keeping all members of Ostrom's (I998) family of rationality models alive!

More generally, both Berkes and Colding and Folkes usefully elaborate on the importance of examining how common-property-management regimes relate to resource dynamics over time. We recognize the value in this shift of frame away from the individual to the institutional level, since (as Colding and Folke explain) identifying how conservation outcomes are generated (whether these outcomes are "epiphenomenal" or not) can be highly instructive for environmental activists and scholars. Just as we (as evolutionary ecologists) see the importance of what they are doing, so all of the commonproperty theorists here (Berkes, Colding and Folke, and Ostrom) view our game analysis predicated on individual self-interest as complementary to their own work. Would that other disciplines in the social sciences could agree so politely to differ in emphasis!

Still in the context of common-property management, Little makes the very valid point that models such as those we use assume that herding decisions are made with perfect knowledge. It is clear that individuals can never know every outcome associated with each strategic option, particularly when such outcomes are contingent on what everyone else in the population does. This is one reason Ostrom (I998) argues for the concept of "bounded" rationality, rationality constrained by knowledge and community values. With respect to the pastoral case at hand, we would argue (on the basis of ethnographic experiences surely very similar to Little's) that successful herders are acutely aware of the pasture conditions in their region, travel a lot, and discuss rangeland conditions, water, microclimatic variations, disease risk, security, and other relevant factors at great length at ceremonial gatherings, cattle auctions, and other events where herders congregate; some of the ways in which these decisions are made are helpfully elaborated on by Galaty, Fratkin, and Little. As concerns mobility options, we would probably all agree that knowledge is not perfectly accurate but is extensive and frequently updated.
3. Comments are somewhat more mixed as regards the appropriateness of the Barabaig example. The commentators' views on this correlate with the distance of their research sites from Hanang. Thus Homewood and Prins, who have both worked with nearby Masai, seem dissatisfied (or know too much!), whereas Fratkin, Galaty, and Little find considerable heuristic value in our example. Furthermore, many of the ethnographic nuances Galaty suggests (when to leave the wet-season pasture, how to trade off visits to water and graze, how to avoid crowding, etc.) are, as he recognizes, equally amenable to this type of asymmetric analysis by wealth.

Little chides us for unduly privileging the individual as a decision maker. He is quite right-the term was being used as a shorthand for the herd manager, a position that falls to an individual by dint of his position in the extended household, lineage, or clan. We did not intend this term to hide conflicts of interest within herdowning units and have indeed written about such dynamics at length elsewhere (Borgerhoff Mulder and Sellen 1994, Sellen 1999). However, as Galaty says and as our own experiences in pastoralist households confirm, most day-to-day herding decisions are taken by the household head. We thus feel at ease referring to individuals as decision makers.

We wish to consider in more detail one last recurring and important criticism of our example, that forage at the wet-season pasture is of higher quality than on the Barabaig Plains. Indeed, Lane suggests this on the basis of Barabaig ethnobotany, and Galaty, Homewood, and Prins suspect as much on the basis of other ethnographic cases. Our differences here are quite simple. We set up the model to make it as difficult as possible to get conservation arising for purely individual short-term economic benefits because of the question that intrigued us ("under what conditions can conservation arise for purely selfish reasons?"). Wanting there to be as few economic incentives as possible to leave the Barabaig Plains, we treated the nutritional value of the grass as the same. Empiricists question whether this is a good characterization of the Barabaig case. We acknowledged these problems as well as the unusual pattern of grazing transhumance shown by the Barabaig. On the basis of admittedly limited data we stick by our original claim that there are costs to leave the Barabaig Plains that affect households differently and our statement that the Barabaig Plains serve as a grazing reserve for dry-season fodder for two reasons. First, we have been told of cases (from Barabaig settled in Eyasi I987-89) where individuals described having been fined for not removing their principal herds from the environs of Lake Balangdua Lelu and adjacent plains in the wet season; the existence of fines in this context suggests that herders cannot always take their cattle to the wet-season pastures despite the superiority of those grasses. Second, Lane himself concludes that Barabaig favor seasonal grazing rotations because they know that "not only are these areas more productive at these times, but ... pastures need time to recover if they are to be fully productive at a later date" (I996:I08). One final point concerns Prins's suggestion 
that pasture quality is actually better with increased grazing pressure (up to a point); we consider whether this would make coercion of the poor by the rich even more likely, particularly in cases where the poor are many or have relatively large herds. In short, we are pleased to see our critics thinking carefully about the mechanisms underlying this particular ethnographic example of grazing reserves (is it stinting, short-term economic maximization, epiphenomenal conservation, or a long-term economic strategy?); this marks a big step from the days when anthropologists assumed that indigenous peoples, including pastoralists, naturally practiced conservation strategies. If our example turns out to be more of an allegory or metaphor than a real case, we will be in good company!

Finally, as regards the pastoral ethnography, we detect some dismay in Homewood's commentary at our apparent ignorance of the contemporary conditions of pastoralism in Africa. We are of course very cognizant of the fact that pastoralists operate in a world where decisions over rangeland are primarily influenced by land markets, tourism, and warfare (Niamir-Fuller I998, Norton-Griffiths I998); the specific relevance of this for the utility functions of rich herders was discussed above. But Homewood's argument raises a more general issue that we find troubling. While we thoroughly endorse investigation into the political and economic factors (at regional, national, and global scales) impinging on 2othcentury pastoralists (Hjort and Salih I989), we see a dangerous tendency among political ecologists to trace the causes of environmental degradation ever deeper into history and farther into world systems. The danger is that our attention drifts to far-off times and places, leaving unexamined the here-and-now tradeoffs that individual herders face. Yes, political and economic factors are indeed critical in shaping the world in which modern, and no doubt ancient, pastoralists live. But, no, this is not a sufficient analytical framework in itself. We need to study how these factors shape the constraints and opportunities an individual faces, and game theory is a good tool for doing so. With attention glued to distal regional and geopolitical economic factors, it is difficult both to understand the dynamics of local-level change and to develop clear recommendations for how community-based institutions can be rebuilt and supported. We therefore see the myopic focus of this paper as complementary to Homewood's position and in no sense as a deficiency.

4. As to the implications of our work for conservation, we can be mercifully brief. We are of course aware that the long-term success of pastoral grazing systems is predicated less on day-to-day grazing decisions ("overgrazing ${ }^{\prime \prime}$ ) than on the dynamic, nonequilibrial processes outlined by Ellis and Swift (I988), Sandford (I982), and many others. This point is touched on by Galaty but is central to Homewood's and Prins's critiques. Prins claims that our model has "nothing to do with conservation (that is, setting an area aside for future use), let alone with biodiversity conservation," and in a sense he is quite right. As we mentioned at the outset, we unintentionally opened a can of worms in asking (in the title) whether East African pastoralists were truly conservationists. Luckily the majority of our commentators appreciate that our article was meant as a theoretical exploration of the mechanisms whereby conservation behavior (or stinting) arise rather than a treatise on conservation and pastoralism. We suspect, however, that our differences with Homewood and Prins hinge ultimately on a confusion of time scales. Their critique is that grazing does not affect year-to-year grassland productivity and thus our aim of demonstrating long-term conservation is fundamentally misconstrued. We agree that the model may not be applicable to a discussion of the preservation of year-to-year productivity, but this was not our goal. Rather, our model looked at single-year cycles and asked whether pastoralists can conserve-or reserve might be a better word-areas for use later in the year. This is a short time scale in the context of most discussions of conservation, but it is a very long time scale relative to that used in optimal-foraging studies.

Finally, we very much share Galaty's concern that our argument could be used against pastoralists in their claims to land rights if they are shown not to conserve resources. We wish to reiterate our commitment to the fact that evidence of conservation (or the lack thereof) is not a valid criterion for assigning or, rather, reassigning rights to traditionally held lands.

\section{References Cited}

ACHESON, J., AND J. WILSON. I996. Order out of chaos: The case for parametric fisheries management. American Anthropologist 93:579-94.

A GRA W A L , A. I994. "Rules, rule making, and rule breaking: Examining the fit between rule systems and resource use," in Rules, games, and common pool resources. Edited by E. Ostrom, J. Walker, and R. Gardner. Ann Arbor: University of Michigan Press.

A L C O R N , J. B. I989. "The traditional agricultural ideology of Bora and Huastec resource management and its implications for research," in Resource management in Amazonia: Indigenous and folk strategies. Edited by D. A. Posey and W. Balée, pp. 3I-62. Advances in Economic Botany.

. I99I. "Ethics, economies, and conservation," in Biodiversity: Culture, conservation, and codevelopment. Edited by M. L. Oldefield and J. B. Alcorn, pp. 3 I7-49. Boulder: Westview Press.

- I995. Comment on: Intraspecific prey choice by Amazonian hunters, by M. Alvard. CURRENT ANTHROPOLOGY 36:802-3. A L P E R T, P. I996. Integrated conservation and development projects: Examples from Africa. Biodiversity 46:845-55.

ALVARD, M. I993. A test of the ecologically noble savage hypothesis: Interspecific prey choice by neotropical hunters. $\mathrm{Hu}$ man Ecology 2 I:35 5-87.

. I994. Conservation by native peoples: Prey choice in a depleted habitat. Human Nature 5:1 27-54.

- I995. Intraspecific prey choice by Amazonian hunters. CURRENT ANTHROPOLOGY 36:789-8I8.

I998. Evolutionary ecology and resource conservation. Evolutionary Anthropology 7:62-74.

A NDERSON, A THOLL. I997 "Prehistoric Polynesian impact on the New Zealand environment: Te whenua hou," in Historical 
ecology in the Pacific islands: Prehistoric environmental and landscape change. Edited by Patrick V. Kirch and Terry L. Hunt, pp. 27I-83. New Haven: Yale University Press. [EAs] BEAUCAGE, P., AND TALLER DE TRADICIÓN ORAL DEL C E P E C. I 997. Integrating innovation: The traditional Nahua coffee-orchard (Sierra Norte de Puebla, Mexico). Journal of Ethnobiology $17: 45-67$. [FB]

BECKERMAN, S., AND P. VALENTINE. I996. On native American conservation and the tragedy of the commons. CURRENT ANTHROPOLOGY 37:659-6I.

B EHNKE, R. I983. Production rationales: The commercialisation of subsistence pastoralism. Nomadic Peoples I4:3-34. [KH]

BEHNKE, R., AND I. SCOONES. I993. "Rethinking range ecology: Implications for rangeland management in Africa," in Range ecology at disequilibrium: New models of natural variability and pastoral adaptation in African savannas. Edited by R. Behnke, I. Scoones, and C. Kerven, pp. I-30. London: Overseas Development Institute. [KH]

BELL, R. I982. Effect of soil nutrient availability on community structure in African ecosystems. Ecological Studies 42: I93-2I6. [KH]

B EN NET T, J. W. I976. The ecological transition: Cultural anthropology and human adaptation. Oxford: Pergamon Press.

BENSON, K., AND D. STEPHENS. I996. Interruptions, tradeoffs, and temporal discounting. American Zoologist 36:506-I7.

BERGSTROM, T., L. BLOME, AND H. VARIAN. I986. On the private provision of public goods. Journal of Public Economics 29:25-49.

B ERKES , F. I987. "Common-property resource management and Cree Indian fisheries in subartic Canada," in The question of the commons: The culture and ecology of communal resources. Edited by B. J. McCay and J. M. Acheson, pp. 66-9I. Tucson: University of Arizona Press.

- I989. Common property resources: Ecology and community-based sustainable development. London: Belhaven Press.

. I999. Sacred ecology: Traditional ecological knowledge and resource management systems. Philadelphia and London: Taylor and Francis. [FB]

BERKES, F., AND CARL FOLKE. Editors. I998. Linking social and ecological systems: Management practices and social mechanisms for building resilience. Cambridge: Cambridge University Press. [FB, JC, CF]

BIRDSELL, J. I958. On population structure in generalized hunting and collecting populations. Evolution I2:I89-205. B ORGERHOFF MULDER, M. I99I. Datoga pastoralists of Tanzania. National Geographic Research and Exploration 7(2): I66-87.

- I998. "The relevance of the polygyny threshold model to humans," in Human mating patterns. Edited by C. G. N. Mascie-Taylor and A. J. Boyce, pp. 209-30. Cambridge: Cambridge University Press.

- I999. On pastoralism and inequality. CURRENT ANTHROPOLOGY 40:366-67.

B ORGERHOFF MULDER, M., AND L. M. RUTTAN. 2000 "Grassland conservation and the pastoralist commons," in Conservation and behaviour. Edited by L. M. Gosling, W. J. Sutherland, and M. Avery. Cambridge: Cambridge University Press.

B ORGERHOFF MULDER, M., AND D. W. SELLEN. I 994.

"Pastoralist decision making: A behavioral ecological perspective," in African pastoralist systems: An integrated approach. Edited by E. Fratkin, K. A. Galvin, and E. A. Roth, pp. 205-29. Boulder: Lynne Rienner.

B ORGERHOFF MULDeR, M., D. SiefF, AND M. MERUS. 1989. Datoga history in Ngorongoro Crater. Swara I2(2):32-35. в OYD, R., AND P. J. RICHERSON. I985. Culture and the eVolutionary process. Chicago: University of Chicago Press. . I992a. Punishment allows the evolution of cooperation (or anything else) in sizable groups. Ethology and Sociobiology I $3:$ I 7 I -95

I $992 b$. "How microevolutionary processes give rise to history," in History and evolution. Edited by M. H. Nitecki and D. V. Nitecki, pp. I79-2 Io. Albany: State University of New York Press.

B RADB URD, D. I982. Volatility of animal wealth among Southwest Asian pastoralists. Human Ecology 10:85-106.

B R O C K I NGT O N, D . I998. Land loss and livelihoods: The effects of eviction on pastoralists moved from the Mkomazi Game Reserve, Tanzania. Ph.D. diss., University of London, London, England. [KH]

BROCKINGTON, D., AND K. HOMEWOOD. I998. "Pastoralism around Mkomazi Game Reserve: The interaction of conservation and development," in Mkomazi: The ecology, biodiversity, and conservation of a Tanzanian savanna. Edited by M. Coe, N. McWilliam, G. Stone, and M. Packer. London: Royal Geographical Society (with the Institute of British Geographers). [KH]

BROMLEY, D. W., AND M. M. CERNEA. I989. The management of common property natural resources: Some conceptual and operational fallacies. World Bank Discussion Papers 57.

BROUGHTON, JACK M. I994. Declines in mammalian foraging efficiency during the late Holocene, San Francisco Bay, California. Journal of Anthropological Archaeology I 3:37 I-4OI [EAs]

B ULMER, R. N. H. I982. "Traditional conservation practices in Papua New Guinea," in Traditional conservation in Papua New Guinea: Implications for today. Edited by L. Morauta, J. Pernetta, and W. Heaney, pp. 59-78. Boroko, Papua New Guinea: Institute of Applied Social and Economic Research.

CAUGHLEY, G. I993. Elephants and economics. Conservation Biology 7:943-45. [KH]

C H A P M A N M. I985. Environmental influences on the development of traditional conservation in the South Pacific region. Environmental Conservation I 2:2 I 7-30.

CIRIACY-WANTRUP, S. V., AND R. C. BISHOP. I975. "Common property" as a concept in natural resources policy. Natural Resources Journal I 5:7 I 3-27.

CLARK, C. W. I973. The economics of overexploitation. Science I8I:630-34.

ClUtT ON-BROCK, T. H., AND G. A. PARKer. I995a. Punishment in animal societies. Nature 373:209-16.

- I995b. Sexual coercion in animal societies. Animal Behavior 49:I345-65.

COLDING, J., AND C. FOLKE. I997. The relations among threatened species, their protection, and taboos. Conservation Ecology (online) I(I):6 (http://www.consecol.org/voli/issI/art6). [JC, CF]

. I999. Social taboos: "Invisible" systems of local resource management and biodiversity conservation. Beijer Discussion Paper Series I2 I. [JC, CF]

CONELly, W. ThOMAS. I992. Agricultural intensification in a Philippine frontier community: Impact on labor efficiency and farm diversity. Human Ecology 20:203-23 [FB]

CONNOR, R. C. I995. The benefits of mutualism: A conceptual framework. Biological Review 70:427-57.

CORDELL, J. C. I 984 . Defending customary inshore sea rights. Senri Ethnological Studies 17:30I-26.

DAVIS, A., AND C. BAILEY. I996. Common in custom, uncommon in advantage: Common property, local elites, and alternative approaches to fisheries management. Society and Natural Resources 9:25 I-65.

DE BOER, W. F., AND H. H. T. PRINS. I989. Decisions of cattle herdsmen in Burkina Faso and optimal foraging models. Human Ecology I7:445-64. [HнTP]

DiETZ, T ON. I996. Entitlements to national resources: Contours of political environmental geography (Inaugural Lecture, University of Amsterdam). Utrecht: International Books. [кн]

DUANY, WAL. I987. "Constitutional arrangements and the possibility of self-government," in The search for peace and unity in the Sudan. Edited by Francis Deng and Prosser Gifford, pp. I29-39. Washington, D.C.: Wilson Center Press. [EO]

. I992. The Nuer concept of covenant and covenantal way of life. Publius: The Journal of Federalism 22:67-89. [EO]

DU GA TKIN, L. A. I997. The evolution of cooperation: Four paths to the evolution and maintenance of cooperative behavior. BioScience 47:355-62. 
DURNING, A. T. I993. Guardians of the land: Indigenous peoples and the health of the earth. Worldwatch Paper I2.

DY S ON-HUDSON, R., AND N. DYSON-HUDSON. I969. Subsistence herding in Uganda. Scientific American 220:76-89.

EDNEY, J. J., AND C. S. HARPER. I 978 . The effects of information in a resource management problem: A social trap analog. Human Ecology 6:387-95.

ELLIS, J. E., AND D. M. SWIFT. I988. Stability of African pastoral ecosystems: Alternate paradigms and implications for development. Journal of Range Management 4I:450-59. [кн]

ENSMINGER, J., AND J. KNIGHT. I997. Changing social norms: Common property, bridewealth, and clan exogamy. CURRENT ANTHROPOLOGY 38:I-24.

FEENY, D., F. BERKES, B. J. MCCAY, AND J. M. ACHESON. I990. The tragedy of the commons: Twenty-two years later. Human Ecology I 8:I-I9.

FI E N U P - R I O R D A N, A. I 990. Eskimo essays. New Brunswick and London: Rutgers University Press. [FB]

FOLKE, C., L. PRITCHARD JR., J. COLDING, F. BERKES, AND U. SVEDIN. I998. The problem of fit between ecosys tems and institutions. International Human Dimensions Programme on Global Environmental Change Working Paper 2 (www.uni-bonn.de/IHDP/public.htm). [JC, CF]

F R A T K IN, E. I989. Household production and gender inequality in Ariaal Rendille pastoral production. American Anthropologist 9I:45-55.

. I997. Pastoralism: Governance and development issues. Annual Review of Anthropology 26:235-6I.

- I998. Ariaal pastoralists of northern Kenya: Surviving drought and development in Africa's arid lands. Needham Heights, Mass.: Allyn and Bacon. [eF]

FRATKIN, E., AND E. A. ROTH. I99O. Drought and economic differentiation among Ariaal pastoralists of Kenya. Human Ecology I 8:385-402.

fRAtKin, e., E. A. ROth, AND K. A. Galvin, I994. African pastoralist systems. Boulder: Lynne Rienner. [EF]

FRATKIN, E., AND K. S MITH. I994. "Labor, livestock, and land: The organization of pastoral production," in African pastoralist systems: An integrated approach. Edited by E. Fratkin, K. A. Galvin, and E. A. Roth, pp. 9I-II 2. Boulder: Lynne Rienner.

GADGIL, M., AND F. BERKES. I99I. Traditional resource management systems. Resource Management and Optimization 8:I27-4I.

G A L A T Y , J . G. I993. "The pastoralist's dilemma: Common property and enclosure in Kenya's rangeland," in Food systems under stress in Africa: African-Canadian Research Cooperation, Proceedings of a Workshop 7-8 November I992, Ottawa, Ontario, Canada. Edited by R. Vernooy and K. M. Kealey, pp. IOO-II3.

- I994. "Rangeland tenure and pastoralism in Africa," in African pastoralist systems: An integrated approach. Edited by E. Fratkin, K. A. Galvin, and E. A. Roth, pp. 9I-II2. Boulder: Lynne Rienner.

GEERTZ, C L IF F ORD. I963. Agricultural involution. Berkeley: University of California Press. [FB]

GIBSON, C. C., AND S. A. MARKS. I995. Transforming rural hunters into conservationists: An assessment of communitybased wildlife management programs in Africa. World Development 23:94I-56.

GIBSON, CLARK, MARGARET MCKEAN, AND ELINOR OSт Rо M. Editors. 2000. People and forests: Communities, insti tutions, and the governance of forests. Cambridge: MIT Press. [EO]

GORDON, H. S. I954. The economic theory of a common property resource: The fishery. Journal of Political Economy 62: I 24-42.

GRAB OW SKI, R. I988. Theory of induced institutional innovation: A critique. World Development I 6:385-94.

GUNDERSON, L., C. S. HOLLING, AND S. LIGHT. I995. Barriers and bridges to the renewal of ecosystems and institutions. New York: Columbia University Press [JC, CF]

HAMES, R. I987. "Game conservation of efficient hunting," in
The question of the commons: The culture and ecology of communal resources. Edited by B. J. McCay and J. M. Acheson, pp. 92-107. Tucson: University of Arizona Press.

. I99 I. "Wildlife conservation in tribal societies," in Biodiversity: Culture, conservation, and ecodevelopment. Edited by M. L. Oldfield and J. B. Alcorn, pp. I72-99. Boulder: Westview Press.

HANNA, S., S. C. FOLKE, AND K.-G. MALER. Editors. I996. Rights to nature: Ecological, economic, cultural, and political principles of institutions for the environment. Washington, D.C.: Island Press.

HARDIN, G. I968. The tragedy of the commons. Science I62: I 243-48.

HERREN, U. J. I990. Socioeconomic stratification and small stock production in Mukogodo Division, Kenya. Research in Economic Anthropology i 2:I I I-48.

HILL, K. I995. Comment on: Intraspecific prey choice by Amazonian hunters, by M. Alvard. CURRENT ANTHROPOLOGY 36: $805-7$.

H I т С С ОСк, R. I990. "Water, land, and livestock: The evolution of tenure and administration patterns in the grazing area of Botswana," in The world of pastoralism: Herding systems in comparative perspective. London: Guilford Press and Belhaven Press. Edited by D. Johnston and J. Galaty, pp. 2I6-55. [KH]

HJORT, A., AND M. A. R. M. SALIH. I989. Ecology and politics: Environmental stress and security in Africa. Uppsala: Scandinavian Institute of African Studies.

HOGG, R. I990. "The politics of changing property rights among Isiolo Boran pastoralists in northern Kenya," in Property, poverty, and people. Edited by P. T. W. Baxter, pp. 20-3 I. Manchester: Department of Social Anthropology and International Development Centre, University of Manchester.

HOLLING, C. S., AND G. K. MEFFE. I996. Command and control and the pathology of natural resource management. Conservation Biology 10:328-37. [JC, CF]

HOMEWOOD, K., AND D. BROCKINGTON. n.d. "Biodiversity, conservation, and development in Mkomazi Game Reserve, Tanzania," in Tropical open woodlands. Global Ecology and Biogeography 8 . In press. $[\mathrm{KH}]$

HOMEWOOD, K., H. KI WASILA, AND D. BROCKINGTON. 1997. Conservation with development? The case of Mkomazi, Tanzania. Final Research Report to ESCOR-ODA, Department for International Development, London. [KH]

HOMEWOOD, K. M., AND W. A. RODGERS. I99I. Maasailand ecology. Cambridge: Cambridge University Press.

HUNN, E. I982. "Mobility as a factor limiting resource use in the Columbian Plateau of North America," in Natural resource managers: North American and Australian hunter-gath erers. Edited by N. Williams and E. Hunn, pp. I7-43. Boulder: Westview Press.

H U N T I N G F O D , G. W. B. I953a. The northern Nilo-Hamites. (Ethnographic Survey of Africa pt. 6.) London: International African Institute. [нHтP]

- I953b. The southern Nilo-Hamites. (Ethnographic Survey of Africa pt. 8.) London: International African Institute. [НнтP] HYDEN, G. I990. "Reciprocity and governance in Africa," in The failure of the centralized state: Institutions and self-governance in Africa. Edited by J. S. Wunsch and D. Olowu. Boulder: Westview Press.

IIED (INTERNATIONAL INSTITUTE FOR ENVIRONMENT And Development). I994. Whose Eden? An overview of community approaches to wildlife management. London.

I WGIA (INTERNATIONAL WORKING GROUP ON INDIGEN OUS AFFAIRS). I992. "Declaration by the Indigenous Peoples," in IWGIA Yearbook I99I, pp. I 57-63. Copenhagen.

j о с н п м, M. A. I98 I. Strategies for survival. New York: Academic Press.

JOHANNES, R. E. I978. Traditional marine conservation methods in Oceania and their demise. Annual Review of Ecological Systematics 9:349-64.

- I98I. Words of the lagoon. Berkeley: University of California Press.

—. I998. Government-supported, village-based management 
of marine resources in Vanuatu. Ocean and Coastal Management 40:I65-86. [JC, CF]

K A P L A N, H., AND K. HILL. I992. "The evolutionary ecology of food acquisition," in Evolutionary ecology and human behaviour. Edited by E. A. Smith and B. Winterhalder, pp. I67-20I. New York: Aldine de Gruyter.

KA PLAN, Н., AND K. K О ISHKE. I992. "Resource use, traditional technology, and change among native peoples of lowland South America," in Conservation of neotropical forests. Edited by K. H. Redford and C. Padoch, pp. 83-107. New York: Columbia University Press.

K А , J. I985. Native Americans in the fur trade and wildlife depletion. Environmental Review 9: I 8-30.

K E TELAARS, J. J. M. H. I 986. "Prediction of feeding intake in ruminants," in Modelling of extensive livestock production systems. Edited by N. de Ridder, H. van Keulen, N. G. Seligman, and P. J. H. Neate, pp. Io8-6r. Addis Ababa: International Livestock Centre for Africa. [HTTP]

K L I M A, G. I964. Jural relations between the sexes among the Barabaig. Africa 34:9-19.

- I965. Kinship, property, and jural relations among the Barabaig. Ph.D. diss., University of California, Los Angeles, Calif.

. 1970. The Barabaig: East African cattle herders. New York: Holt, Rinehart and Winston. [HнTP]

LA M PREY, H. F. I983. "Pastoralism yesterday and today: The overgrazing problem," in Tropical savannas. Edited by F. Bourlière, pp. 643-66. Amsterdam: Elsevier.

LANE, C. I990. Barabaig natural resource management: Sustainable land use under threat of destruction. United Nations Research Institute for Social Development Discussion Paper I 2 .

- I996. Pastures lost: Barabaig economy, resource tenure, and the alienation of their land in Tanzania. Nairobi: Initiatives Publishers.

L A N S I G, J. S. I988. Balinese "water temples" and the management of irrigation. American Anthropologist 89:326-4I.

LEACH, E. R. I972. "Anthropological aspects: Conclusion," in Population and pollution. Edited by P. R. Cox and J. Peel, pp. 37-40. New York: Academic Press.

LEGESSE, A. I973. Gada: Three approaches to the study of African society. London: Collier Macmillan.

L I T T LE, PETER D. I996. Pastoralism, biodiversity, and the shaping of savanna landscapes in East Africa. Africa 66:37-5 I [PDL]

LitTle, M. A., AND P. W. Leslie. Editors. I998. Turkana herders of the dry savanna: Ecology and biobehavioral response of nomads to an uncertain environment. New York: Oxford University Press. [EF]

L OW, B. s. I996. Behavioral ecology of conservation in traditional societies. Human Nature 7:353-79.

M С С А в Е, J. т. I990. Turkana pastoralism: A case against the tragedy of the commons. Human Ecology i 8:8 I-IO3.

- I997. "Patterns and process of group movement in human nomadic populations: A case study of the Turkana of northwestern Kenya," in On the move: How and why animals travel in groups. Edited by S. Boinski and P. A. Garber. Chicago: University of Chicago Press.

MCCAY, в. J., AND J. M. ACHESON. Editors. 1987. The question of the commons: The culture and ecology of communal resources. Tucson: University of Arizona Press.

MCKEAN, M. A. I992. Success on the commons: A comparative examination of institutions for common property resource management. Journal of Theoretical Politics 4:247-8I.

MARTIN, P. S., AND R. G. KLEIN. I984. Quaternary extinctions: A prehistoric revolution Tucson: University of Arizona Press. [HнTP]

MAY, R. I994. Resource exploitation and the economics of extinction. Nature 372:42-43. [KH]

metcAlfe, s. I994. "The Zimbabwe Communal Areas Management Programme for Indigenous Resources (CAMPFIRE)," in Natural connections: Perspectives in community-based con- servation. Edited by D. Western and M. Wright, pp. I6I-92. Washington, D.C.: Island Press.

MURAGURI, K. I999. Land tenure killing off pastoralism. Horizon: Daily Nation on the Web (www.nationaudio.com/News/ Daily Nation/I 50499/Features/XX $5 . h t m l) . ~[\mathrm{KH}]$

NELSON, R. I982. "A conservation ethic and environment: The Koyukon of Alaska," in Resource managers: North American and Australian hunter-gatherers. Edited by N. Williams and E. Hunn, pp. 2 I I-28. Boulder: Westview Press.

NE T T I NG, R. M. I976. What alpine peasants have in common: Observations on communal tenure in a Swiss village. Human Ecology 4:I35-46.

NIA M I R - F ULLER， M. I998. "The resilience of pastoral herding in Sahelian Africa," in Linking social and ecological systems. Edited by F. Berkes and C. Folke, pp. 250-84. Cambridge: Cambridge University Press.

N O R T O N-GR I F FI TH S, M. I998. "The economics of wildlife conservation policy in Kenya," in Conservation of biological resources. Edited by E. J. Milner-Gulland and R. Mace, pp. 279-93. Malden, Mass.: Blackwell Science. [KH]

OL S O , M. I967. The logic of collective action. Cambridge: Harvard University Press.

O S т R O M, E. I990. Governing the commons: The evolution of institutions for collective action. Cambridge: Cambridge University Press.

- I 998. A behavioral approach to the rational choice theory of collective action. (Presidential Address, American Political Science Association, I 997.) American Political Science Review 92:I-22

OStrom, E., J. WALKER AND R. GARDNer. I992. Covenants with and without a sword: Self-governance is possible. American Political Science Review 86:404-17.

- I994. Rules, games, and common pool resources. Ann Arbor: University of Michigan Press.

OSTROM, ELINOR, JOANNA BURGER, CHRISTOPHER FIELD, RICHARD B. NORGAARD, AND DAVID POLICAN SKY. I999. Revisiting the commons: Local lessons, global challenges. Science 284(54I2): 278-82. [EO, EAS]

OTA ( OFFICE OF TECHNOLOGICAL ASSESSMENT, U.S. C O NGRESS). I987. Technologies to maintain biological diversity. Washington, D.C.: U.S. Government Printing Office.

PETERS, P. E. I987. "Embedded systems and rooted models: The grazing lands of Botswana and the commons debate," in The question of the commons:The culture and ecology of communal resources. Edited by B. J. McCay and J. M. Acheson, pp. I7 I-94. Tucson: University of Arizona Press.

POSEY, D. A., AND W. BALÉE. Editors. I989. Resource management in Amazonia: Indigenous and folk strategies. Advances in Economic Botany 7.

PRATCHET, D., B. G. CAPPER, D. E. LIGHT, M. D. MILLER, A. S. RUTHERFORD, T. W. RENNIE, N. G. BUCK, AND J. C. TRAIL. I977. Factors limiting live weight gain of beef cattle on rangelands in Botswana. Journal of Range Management 30:442-45.

PRINS, H. H. T. I992. The pastoral road to extinction: Competition between wildlife and traditional pastoralism in East Africa. Environmental Conservation I 9: I I 7-23.

- I996. Behaviour and ecology of the African buffalo: Social inequality and decision making. London: Chapman and Hall. [HHTP]

PURI, R. K. I995. Comment on: Intraspecific prey choice by Amazonian hunters, by M. Alvard. CURRENT ANTHROPOLOGY 36:809-IO.

REDFORD, к. I990. The ecologically noble savage. Orion $\mathrm{Na}$ ture Quarterly 9:25-29.

ROGERS, A. R. I99I. Conserving resources for children. Human Nature 2:73-82.

ROGERS, P., D. BROCKINGTON, H. KIWASILA, AND K. HOMEW O OD. I998. "Environmental awareness and conflict genesis: People versus parks in Mkomazi Game Reserve," in Managing the globalised environment. Edited by T. Granfelt. London: Intermediate Technology Publications. [KH]

RUNGE，C. F. I98 I. Common property externalities: Isolation, 
assurance, and resource depletion in a traditional grazing context. American Journal of Agricultural Economics 63:595-606. I984. Institutions and the free rider: The assurance problem in collective action. Journal of Politics 46:I54-8I.

RUTTAN, L. M. I998. Closing the commons: Cooperation for gain or restraint? Human Ecology 26:43-66.

SAND F ORD, S. I982. "Pastoral strategies and desertification: Opportunism and conservation in drylands," in Desertification and development: Dryland ecology in social perspective. Edited by B. Spooner and H. Mann, pp. 6I-80. London and New York: Academic Press.

- I983. Management of pastoral development in the Third World. London: John Wiley.

SCOONES, I. Editor. I995. Living with uncertainty: New directions in pastoral development in Africa. London: Intermediate Technology Publications. [JGG]

S CоTT, A. I955. The fishery: The objectives of sole ownership. Journal of Political Economy 63: I I 6-24.

SELLEN, D. W. I999. Polygyny and child growth in a traditional pastoral society: The case of the Datoga of Tanzania. Human Nature. In press.

SEN, A. K. I967. Isolation, assurance, and the social rate of discount. Quarterly Journal of Economics 81: I I 2-24.

SIEFF, D. F. I995. The effects of resource availability on the subsistence strategies of Datoga pastoralists of north-west Tanzania. Ph.D. diss., University of Oxford, Oxford, U.K.

- I997. Herding strategies of the Datoga pastoralists of Tanzania: Is household labour a limiting factor? Human Ecology 25:519-44.

. I999. The effects of wealth on livestock dynamics among the Datoga pastoralists of Tanzania. Agricultural Systems 59: $\mathrm{I}-25$.

SIMON, H. I990. A mechanism for the social selection of successful altruism. Science 250:1665-68.

SL O В O D KIN, L. I968. How to be a predator. American Zoologist 8:43-5 I.

SMITH, E. A. I983. Anthropological applications of optimal foraging theory: A critical review. CURRENT ANTHROPOLOGY 24: $625-5 \mathrm{I}$.

- I995. Comment on: Intraspecific prey choice by Amazonian hunters, by M. Alvard. CURRENT ANTHROPOLOGY 36: 8IO-II.

SPEAR, T. I997. Mountain farmers. Oxford: James Currey/ Berkeley: University of California Press. [KH]

SPERLING, L., AND J. G. GALATY. I990. "Cattle, culture, and economy," in The world of pastoralism: Herding systems in comparative perspective. Edited by J. G. Galaty and D. L. Johnson, pp. 69-98. New York: Guildford Press.

S T E A R M A N, A. M. I994. "Only slaves climb trees." Human Nature 5:339-57.

- I995. Comment on: Intraspecific prey choice by Amazonian hunters, by M. Alvard. CURRENT ANTHROPOLOGY 36: 8 I I-I 2 .

STEPHENS, D. W., AND J. R. KREBS. I986. Foraging theory. Princeton: Princeton University Press.

S TEVENS, S. I997. "Consultation, co-management, and conflict in Sagarmatha (Mount Everest) National Park, Nepal," in Conservation through cultural survival: Indignenous peoples and protected areas. Edited by S. Stevens, pp. 63-97. Washington, D.C.: Island Press.

STONE, M. L. I972. Organized poaching in Kitui District: A failure in district authority, I900-I960. International Journal for African Historical Studies 5:436-52. [HHTP]

S ULlivan, s. I998. People, plants, and practice in Namibian drylands: Socio-political and ecological dimensions of resourceuse by Damara farmers in north-west Namibia. Ph.D. diss., University of London, London, England. [ $\mathrm{KH}]$ n.d. "The impacts of people and livestock on topographically diverse open wood-and-shrublands in arid north-west Namibia," in Tropical open woodlands. Global Ecology and Biogeography $8 .[\mathrm{KH}]$

TOOBY, J., AND L. COSMIDES. I996. "Friendship and the bankers' paradox: Other pathways to the evolution of adaptations for altruism," in Evolution of social behaviour patterns in primates and man. Edited by W. G. Runciman, J. Maynard Smith, and R. I. M. Dunbar, pp. I I9-42. Oxford: Oxford University Press.

TO MIKAWA, M. I979. The migrations and inter-tribal relations of the pastoral Datoga. Senri Ethnological Studies 5:I-46.

VARUGHESE, G., AND E. OSTROM. I998. The contested role of heterogeneity. Bloomington: Indiana University Workshop in Political Theory and Policy Analysis.

VEHRENCAMP, S. L. I983. A model for the evolution of despotic versus egalitarian societies. Animal Behaviour 31:667-82.

VICKERS, W. T. I99I. "Hunting yields and game composition over ten years in an Amazon Indian territory," in Neotropical wildlife use and conservation. Edited by J. G. Robinson and K. H. Redford, pp. 55-8I. Chicago: University of Chicago Press.

. I994. From opportunism to nascent conservation: The case of the Siona-Secoya. Human Nature 5:307-37.

VOETEN, M. M., AND H. H. T. PRINS. n.d. Resource partitioning between sympatric wild and domestic herbivores in the Tarangire region of Tanzania. Oecologia. In press. [HHTP]

WALLER, R. I976. The Maasai and the British I895-1905: The origins of an alliance. Journal of African History 27:529-53. [HHTP]

WALLER, R., AND K. HOMEWOOD. I997. "Elders and experts: Contesting veterinary knowledge in a pastoral community," in Western medicine as contested knowledge. Edited by A. Cunningham and B. Andrews, pp. 69-93. Manchester: Manchester University Press. [KH]

WARREN, D. MICHAEL, AND JENNIFER PINKSTON. I 998 "Indigenous African resource management of a tropical rain forest ecosystem: A case study of the Yoruba of Ara, Nigeria," in Linking social and ecological systems. Edited by F. Berkes and C. Folke, pp. I 5-89. Cambridge: Cambridge University Press. [FB]

WESTERN, D. I975. Water availability and its influence on the structure and dynamics of a savannah mammal community. East African Wildlife Journal I 3:265-86.

W ESTERN, D A VID. I994. "Ecosystem conservation and rural development: The case of Amboseli," in Natural connections: Perspectives in community-based conservation. Edited by David Western, R. Michael Wright, and Shirley Strum, pp. I 5-52. Washington, D.C.: Island Press. [PDL]

WILLIAMS, G. C. I966. Adaptation and natural selection. Princeton: Princeton University Press.

W INTERHALDER, B. P. I977. Foraging strategy adaptations of the boreal forest Cree: An evaluation of theory and models from evolutionary ecology. Ph.D. diss. Cornell University, Ithaca, N.Y.

. I98 I. "Foraging strategies in the boreal environment: An analysis of Cree hunting and gathering," in Hunter-gatherer foraging strategies. Edited by B. Winterhalder and E. A. Smith, pp. 66-98. Chicago: University of Chicago Press. [EAs]

WINTERHALDER, B. P., AND F. LU. I997. A forager-resource population ecology model and implications for indigenous conservation. Conservation Biology i I: I 354-64.

ZANN, L. P. I989. "Traditional management and conservation of fisheries in Kiribati and Tuvalu Atolls," in Traditional marine resource management in the Pacific Basin: An anthology. Edited by K. Ruddle and R. E. Johannes, pp. 77-IO2. Jakarta: UNESCO/ROSTSEA. 